DIW BERLIN

Discussion

Papers
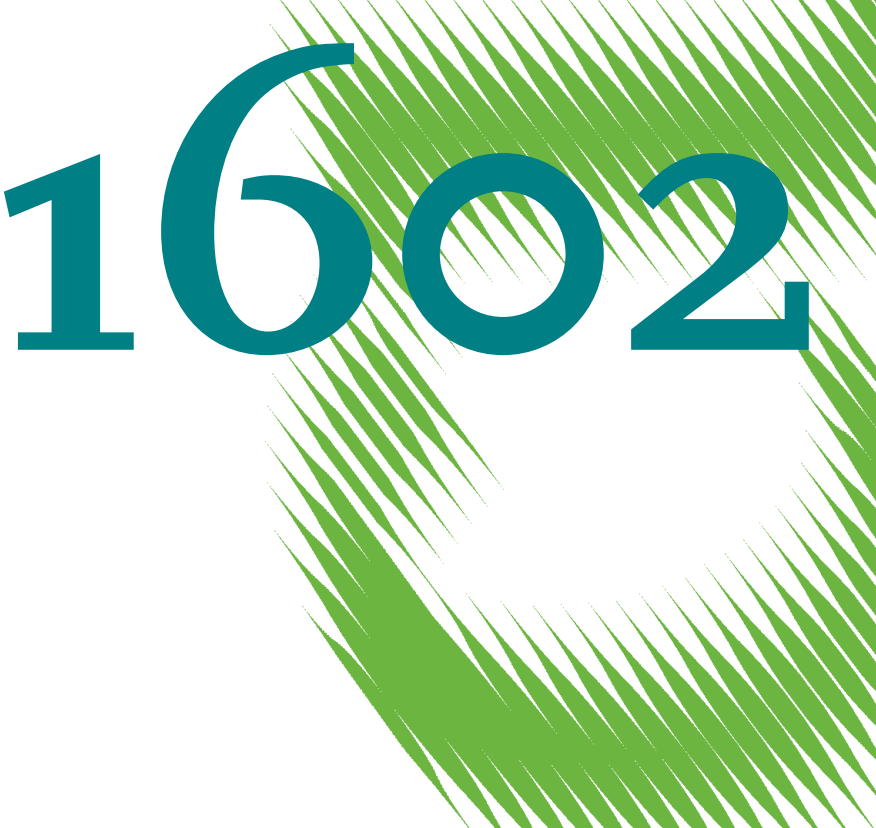

111

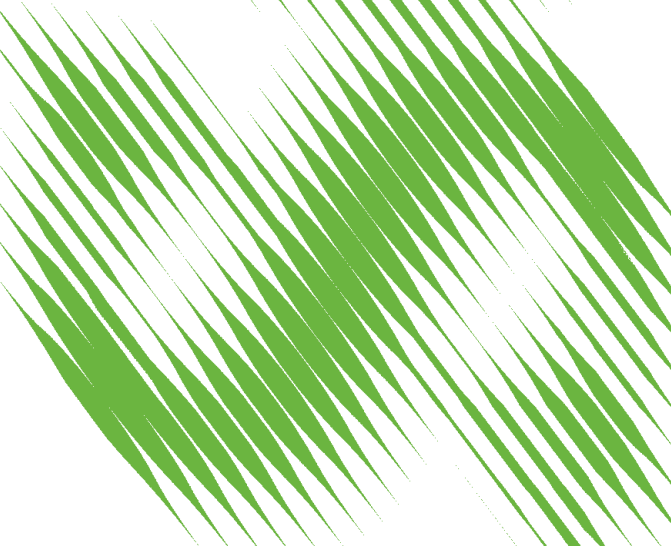

MIM

MIMMMMMMMMT

Ambiguity and Time-Varying Risk Aversion in Sovereign Debt Markets 
Opinions expressed in this paper are those of the author(s) and do not necessarily reflect views of the institute.

IMPRESSUM

(C) DIW Berlin, 2016

DIW Berlin

German Institute for Economic Research

Mohrenstr. 58

10117 Berlin

Tel. +49 (30) $89789-0$

Fax +49 (30) $89789-200$

http://www.diw.de

ISSN electronic edition 1619-4535

Papers can be downloaded free of charge from the DIW Berlin website:

http://www.diw.de/discussionpapers

Discussion Papers of DIW Berlin are indexed in RePEc and SSRN:

http://ideas.repec.org/s/diw/diwwpp.html

http://www.ssrn.com/link/DIW-Berlin-German-Inst-Econ-Res.html 


\title{
Ambiguity and Time-Varying Risk Aversion in Sovereign Debt Markets*
}

\author{
Christoph Grosse Steffen ${ }^{\ddagger} \quad$ Maximilian Podstawski ${ }^{\S}$
}

August 2016

\begin{abstract}
This paper introduces changes in the level of ambiguity as a complementary source of time-varying risk aversion. We show in a consumption-based asset pricing model with simultaneously risky and ambiguous assets that a rise in the level of ambiguity raises investors' risk aversion. The effect is quantified in an application to European sovereign debt markets using a structural VAR to achieve identification in the data. We proxy for ambiguity using a measure of macroeconomic uncertainty and decompose empirically credit default swaps (CDS) for Spain and Italy into three shocks: fundamental default risk, risk aversion, and uncertainty. We find that shocks to uncertainty significantly increase international investors' risk aversion, accounting for about one fifth of its variation at a five week horizon, and have a significant and economically relevant impact on sovereign financing premia.
\end{abstract}

Keywords: Time-varying risk aversion; Ambiguity; Uncertainty; Sovereign debt; Identification via heteroscedasticity; Maxmin

JEL Classifications: C32, D80, E43, G01, H63

\footnotetext{
*We are grateful to participants at the IAAE 2016 (Milan-Bicocca), the Berlin Internal Macroeconomics Workshop 2016, and the Empirical Macroeconomics Workshop at Freie Universität Berlin for insightful discussions and helpful comments to earlier versions this paper. We further benefited from discussions with Wouter den Haan, Matthias Lang, Helmut Lütkepohl, Haroon Mumtaz, Michele Piffer, David Pothier and Tobias Schmidt.

${ }^{\ddagger}$ German Institute for Economic Research (DIW Berlin), Mohrenstraße 58, 10117 Berlin, Germany. Email: cgrossesteffen(at)diw.de.

${ }^{\S}$ German Institute for Economic Research (DIW Berlin), Mohrenstraße 58, 10117 Berlin, Germany. Email: mpodstawski(at)diw.de
} 


\section{Introduction}

Over the course of the European sovereign debt crisis of 2009-2012, affected governments in the euro area faced financial conditions in international capital markets that were challenging for public debt sustainability. In this context, a growing strand of empirical literature shows that public debt of distressed countries was priced at levels that cannot be explained by macroeconomic fundamentals alone. ${ }^{1}$ Instead, a common explanation for the unexplained part in European bond returns was found to be strong variation in investors' risk aversion. ${ }^{2}$ An important issue therefore is to understand which factors lead to changes in risk aversion.

While it is well understood that risk aversion varies with changes in wealth and the level of habit persistence in consumption, ${ }^{3}$ this paper introduces ambiguity about macroeconomic fundamentals as an additional source of variation in investors' risk aversion. Building on the literature that documents that ambiguity aversion increases investors' effective risk aversion, we show theoretically and empirically that exogenous changes in the level of ambiguity induces time-variation in risk aversion. We find that macroeconomic ambiguity explains a relevant share in the sovereign financing premia through two distinct channels: via a first-order effect in form of an ambiguity premium and via a second-order effect by increasing investors' risk aversion. Thereby, the findings are pointing toward ambiguity constituting a root cause for changes in risk attitudes and are part of the research effort attempting to understand the deterioration in financing conditions for European sovereigns.

To explore theoretically the different nature of risk and ambiguity for the pricing of sovereign debt, we use a two-period consumption-based asset pricing model with defaultable bonds. In this model of a small open economy, a benevolent government is rolling over its accumulated stock of debt. It cannot commit to repay and will take an optimal default decision depending on the realization of aggregate productivity. However, the law of motion of the aggregate productivity state is risky and ambiguous, similar to the case in Ilut and Schneider (2014). As a result of ambiguity about the macroeconomic fundamental, the payoffs from holding

\footnotetext{
${ }^{1}$ See, among others, Aizenman et al. (2013), Grauwe and Ji (2012), or D'Agostino and Ehrmann (2014).

${ }^{2}$ Hagen et al. (2011) and Bernoth and Erdogan (2012) document a sharp increase in risk aversion. See a detailed discussion below.

${ }^{3}$ While the classic work of Arrow (1963) and Pratt (1964) depict the role of wealth for risk aversion, Constantinides (1990) and Campbell and Cochrane (1999) made seminal contributions with regard to habit persistence for asset pricing.
} 
government debt turn out to be ambiguous, too. International investors take a consumptionsavings and an investment decision. They can either hold risky and ambiguous government bonds or a riskfree asset. Investor preferences are characterized by three features. First, they exhibit constant relative risk aversion (CRRA). Second, there is habit persistence in the level of consumption. These two assumptions yield variation in the intertemporal elasticity of substitution in consumption that affects investors' risk aversion, depending on the level of habit persistence (Chetty and Szeidl, 2005). Third, investors are sensitive toward the ambiguity surrounding the future aggregate productivity realization. Specifically, we let investors be ambiguity averse according to the maxmin-model of Gilboa and Schmeidler (1989). As a result of multiple priors regarding the possible law of motion for productivity that governs the sovereign's default decision, maxmin preferences make investors act under their worst case prior.

Against the backdrop of this preference structure of investors in the model, we show that a rise in ambiguity increases risk aversion. This is a result from the interaction between a change in the worst case prior of investors in response to a level-shift in ambiguity and decreasing aversion to risk in wealth, a property that arises from external habit persistence in consumption. The intuition is the following: As investors expect with higher ambiguity lower levels of surplus consumption in the future, they tend to be more risk averse today in order to safeguard the future level of habit consumption. We show the conditions for the main mechanism in a parametrized setting within the maxmin-model. ${ }^{4}$ In the empirical part, we provide evidence for the implied testable implication that an increase of macroeconomic ambiguity is followed by a significant rise in an aggregate measure of risk aversion, as predicted by the model. We further use the model to pin down analytically three components, fundamental default risk, risk aversion and ambiguity, in the arising asset pricing equation for defaultable government debt, which we subsequently identify in an empirical model.

Based on the decomposition of sovereign financing premia of our theoretical model, we analyze the role of macroeconomic ambiguity for the pricing of sovereign debt empirically in a structural vector autoregressive (SVAR) model. Since ambiguity is not observable, we proxy for

\footnotetext{
${ }^{4}$ We leave the generalization of this result with respect to different modelling approaches to ambiguity in the $\alpha$-maxmin expected utility framework (Ghirardato et al., 2004) and in the smooth ambiguity framework (Klibanoff et al., 2005) for future research.
} 
ambiguity using an empirical measure of macroeconomic uncertainty. ${ }^{5}$ To this end, we propose a higher frequency measure of economic uncertainty. Specifically, we apply the methodology put forward by Jurado et al. (2015) to a large set of Spanish and Italian equity returns. As a result, we obtain a weekly time series that reflects the underlying economic uncertainty faced by investors, entrepreneurs, and employees alike. We then proceed by using this measure as a proxy for macroeconomic ambiguity in the empirical analysis.

Given the lack of identifying restrictions provided by economic theory, we exploit the statistical properties of the data in order to identify three shocks: A fundamental default risk shock, a risk aversion shock, and an uncertainty shock. We deploy the structural model to empirically assess the relevance of macroeconomic uncertainty for the pricing of Spanish and Italian sovereign debt, decomposing their financing premia into contributions from the three shocks. We find that shocks to macroeconomic uncertainty have a significant impact on sovereign yields. In a historical decomposition, they make up for close to 30 basis points in credit default swaps (CDS) at the onset of the European sovereign debt crisis, while their role diminishes as the sovereign debt crisis unfolds. In addition, changes in uncertainty account for about 20 percent of the variation in risk aversion at a five week horizon in a forecast error variance decomposition, further increasing at larger horizons. Our model provides evidence for macroeconomic ambiguity to play a similar role as time-varying risk aversion for the pricing of sovereign credit risk.

On the empirical side, this paper makes three contributions. Firstly, we propose a higher frequency measure of economic uncertainty based on Jurado et al. (2015). Secondly, we propose an identification of fundamental default risk, risk aversion, and ambiguity shocks within a Markov-switching structural vector autoregressive (MS-SVAR) model that makes use of the data properties following Rigobon (2003) and Lanne and Lütkepohl (2008). Such a statistical identification approach is particularly helpful as economic theory does not offer any structural restrictions that facilitate the disentanglement of risk aversion from ambiguity shocks, which is due to an observational-equivalence result (Hansen et al., 1999), as discussed in detail below.

\footnotetext{
${ }^{5}$ Therefore, we talk about ambiguity in the context of the theoretical model, whereas we adopt the notion of uncertainty for the empirical analysis. The measure of uncertainty is based on forecast error volatility that may result from agents' uncertainty of the probability distribution underlying the process of interest in the sense of Knight (1921). We discuss this in further detail in Section 4.
} 
We label the statistically identified shocks by investigating their contribution to the forecast error variance of the endogenous variables in the SVAR model and confirm the labeling based on the heteroscedasticity pattern of the shocks. Thirdly, we quantify the share in sovereign yields over the most recent period of financial and fiscal distress in the euro area and find that ambiguity shocks account for a relevant share in the financing premium of the countries considered.

The paper is structured as follows. The next section discusses the related literature. In Section 3, we develop a model that studies the role of macroeconomic ambiguity for changes in investors' risk aversion and the pricing of sovereign debt. Section 4 outlines the empirical setup for the analysis of macroeconomic ambiguity for sovereign financing premia. The data set is introduced in Section 5. This section also discusses in greater detail the construction of a high frequency index of macroeconomic uncertainty that we use subsequently as a proxy for ambiguity. Section 6 presents the empirical model used to analyze the relevance of ambiguity shocks for the pricing of sovereign debt, before results are presented in Section 7 . Section 8 concludes.

\section{Relation with the literature}

On the theoretical side, this paper is closely related to the finance literature that explains the equity premium and riskfree rate puzzle through the joint presence of risk and ambiguity. Hansen et al. (1999) show that decision rules of investors with a requirement for robustness are observational equivalent to those of investors with higher levels of risk aversion. Maenhout (2004) and Trojani and Vanini (2004) extend on this result and document that ambiguity aversion leads to state dependence or environment-specific effective risk aversion. We build on this strand of literature that established the result that ambiguity aversion affect decision rules and relative risk aversion. ${ }^{6}$ However, with robust control preferences, as predominantly used in the existing literature, the amount of required robustness is endogenously determined. This paper uses the maxmin-framework for the analysis of exogenous variations in the level of ambiguity that are independent of the fundamental state. Further, we quantify the effects of

\footnotetext{
${ }^{6}$ Alary et al. (2013) extend further on these results. They find that the willingness to pay for self-insurance is, under certain conditions, higher if there is ambiguity aversion on top of risk aversion.
} 
ambiguity on risk aversion empirically using macro data.

With respect to our findings on time-variation in risk aversion through ambiguity, we build on the results of Cherbonnier and Gollier (2015) who analyse how the attitude towards risk, specifically the property of decreasing aversion in wealth in an Arrow-Pratt sense, is affected by the introduction of ambiguity aversion. They show that this property is robust to the introduction of ambiguity aversion in the form of the maxmin-model if preferences feature decreasing concavity and are of the HARA-type, i.e. linear in absolute risk aversion.

Further, this paper is related to quantitative models of sovereign default that analyze the role of investor preferences for pricing of government debt. Arellano (2008) points out that high levels of risk aversion are needed in order to match the average spread on Argentinian sovereign debt. ${ }^{7}$ Borri and Verdelhan (2011) introduce time-varying risk aversion through habit persistence in the utility function and demonstrate that lenders' economic conditions matter for the pricing of sovereign debt. Große Steffen (2015) finds that higher ambiguity about the macroeconomic fundamental increase the yield on public debt if investors are ambiguity averse. This paper is distinct in that it combines ambiguity aversion, risk aversion and habit persistence in consumption on the side of investor preferences in a simplified two-period setup. We show that all three elements are necessary to obtain an effect of ambiguity on time-varying risk aversion.

The empirical results of this paper are related to a growing literature on the determinants of sovereign yields. While Laubach (2009), Borgy et al. (2011) and Hilscher and Nosbusch (2010) find evidence for an important role of fiscal variables on government bond yields in US, European and emerging market data, respectively, fundamentals fall short in explaining the deterioration in sovereign financing conditions. A very prominent explanation for the overpricing of risk during the global financial crisis and the subsequent European sovereign debt crisis is time-variation in investors' risk perception. Barrios et al. (2009), Sgherri and Zoli (2009) and Caceres et al. (2010) empirically analyze the determinants of European sovereign yield spreads during the financial crisis and find evidence for increased global risk aversion in combination with macroeconomic fundamentals to be important drivers for the rise in yield spreads. Hagen et al. (2011) find that markets turned more sensitive toward fiscal measures

\footnotetext{
${ }^{7}$ Lizarazo (2013) shows how risk aversion makes the pricing of sovereign debt sensitive toward investors' stock of accumulated wealth.
} 
after the collapse of Lehman Brothers. Bernoth and Erdogan (2012) also find evidence for timevarying coefficients that determine the impact of fiscal variables for the pricing of sovereign debt and for investors' risk aversion in a semi-parametric approach. Arghyrou and Kontonikas (2012) argue that the European sovereign debt crisis was in fact a currency crisis that diverted into markets for sovereign bonds. They find that during the crisis markets started pricing an international risk factor and macro-fundamentals on a country-by-country basis and report evidence for a contagion of European economies originating in Greece. According to D'Agostino and Ehrmann (2014), time varying risk appetite of investors can explain some increase in European bond yields, but it still falls short of explaining the rise seen in French and Italian data over the crisis period. They conclude that observed yields are due to an overpricing of risk or possible concerns about redenomination of currencies. Further, Aizenman et al. (2013) and Haan et al. (2014) refer to overpricing in selected member countries of the euro area using crosscountry panel data approaches. In a study of risk premia in the CDS market Amato (2005) decomposes the spreads into a default component and a risk premium component. He finds the latter to be highly volatile, supporting the view that changing risk attitudes are important for fluctuations in asset prices. Focusing on the decomposition of sovereign CDS for an extensive set of developed and emerging market economies, Longstaff et al. (2011) find that the risk premium represents about one third of the spreads. Our findings complement and extend this strand of the literature: Firstly, we document how a change in the level of macroeconomic ambiguity was driving risk aversion during the global financial crisis. Secondly, we show that ambiguity has a direct effect for sovereign bond yields which goes beyond fundamentals.

\section{$3 \quad$ A theoretical model}

In this section, we develop a parsimonious two-period model in which investors price defaultable government debt. The default decision depends on the stock of debt and the aggregate level of productivity, which is assumed to be stochastic with an unknown distribution. This approach to modeling ambiguity is meant to reflect the measured uncertainty in the empirical part of the paper. The innovation lies in the chosen preference structure of international investors. Specifically, we are interested in the case where investors are simultaneously risk averse and 
ambiguity averse. Further, habit persistence in consumption gives rise to variations in the degree of relative risk aversion.

In this setup, we consider exogenous changes in the level of ambiguity to study the effects for the pricing decision and portfolio holdings of government debt. We show that changes in the level of ambiguity are a source for time-variation in risk aversion.

\subsection{Environment}

We investigate a small open economy over two periods in discrete time, $t=0,1$. Let the economy be populated by three different agents: a representative household, a government, and a representative international investor. Figure D.8 in Appendix D gives an overview of the timing of events in the model.

Household. The household produces a final tradeable good $y_{t}$ with constant labor input $l$ while taking as given the aggregate level of productivity $z_{t}$, thus $y_{t}=e^{z_{t}} F(l)$. The law of motion for aggregate productivity $z_{t}$ is subject to risk and ambiguity and will be specified below. The household derives utility from consumption in each period with preferences $v\left(c_{0}^{h}, c_{1}^{h}\right)$, where $v^{\prime}>0$ and $v^{\prime \prime}<0$.

Final goods cannot be stored and therefore consumption is given by period $t$ aggregate final good production net of government transfer payments or lump sum taxation, $\tau_{t}$. Thus, the household is respecting a set of period $t$ budget constraints of the form

$$
\begin{gathered}
c_{0}^{h}=y_{0}-\tau_{0}, \\
c_{1}^{h}=y_{1}-\tau_{1} .
\end{gathered}
$$

Technology and ambiguity. The formalization of ambiguity closely follows Große Steffen (2015). ${ }^{8}$ In order to keep the model as parsimonious as possible, the productivity parameter $z_{t}$ is assumed to feature two states, $z_{t} \in\left\{z^{l}, z^{h}\right\}$, with $z^{h}>0$ and $z^{l}<0$. We think of these two states as being sufficient in introducing risk about the future fundamental state of the economy. The values of $z_{t}$ can be interpreted as recessions and booms, respectively. For simplicity, let

\footnotetext{
${ }^{8}$ This approach to modeling uncertainty is based on Ilut and Schneider (2014), adjusted to the simplified setup described here.
} 
aggregate productivity at $t=0$ be deterministic and taking the lower value, $z_{0}=z^{l}$. However, productivity at $t=1$ is uncertain and can take either the low or the high value. This is decided from the realization of a random draw of the stochastic variable $x$, which is uniformly distributed on the interval $\left(x_{l b}, x_{u b}\right)$, i.e. $x \sim \mathcal{U}\left(x_{l b}, x_{u b}\right)$. If the draw exceeds the threshold variable $\bar{x}$, the high productivity level realizes, thus $z_{1}=z^{h}$. Agents know the threshold value $\bar{x}$ and that $x$ is drawn from a uniform distribution. Thereby, future productivity is stochastic, hence risky. Further, ambiguity enters into the law of motion of aggregate productivity. We assume that the exact upper and lower bounds $\left(x_{l b}, x_{u b}\right)$ of the distribution of $x$ are unknown. In order to form expectations about the realization of future productivity, agents have multiple priors about these two parameters, which are specified next.

Let there be an exogenous realization of ambiguity that pins down the set of prior beliefs about the true data generating process that determines productivity. Specifically, agents are assumed to have a priori information about parameters of the distribution, denoted by $\tilde{x}_{l b}^{p}$ and $\tilde{x}_{u b}^{p}$. Then, an ambiguity realization, denoted by $a$, pins down the set of prior beliefs about the true probabilistic model $\mathcal{U}\left(x_{l b}, x_{u b}\right)$ as a symmetric interval around the a priori given parameters $\tilde{x}_{l b}^{p}$ and $\tilde{x}_{u b}^{p}$ according to

$$
\operatorname{supp}^{p}(\mathcal{U}) \in \mathcal{P}=\left\{\begin{array}{l}
x_{l b}^{p} \in\left[\tilde{x}_{l b}-a, \tilde{x}_{l b}+a\right] \\
x_{u b}^{p} \in\left[\tilde{x}_{u b}-a, \tilde{x}_{u b}+a\right]
\end{array}\right.
$$

As a result, prior beliefs about the probability of the high productivity state can be expressed as

$$
\operatorname{Prob}^{p}\left\{z_{1}=z^{h}\right\}=1-\frac{\bar{x}-x_{l b}^{p}}{x_{u b}^{p}-x_{l b}^{p}}
$$

The information structure specific to the productivity process is illustrated in Figure D.9 in Appendix D in the form of a stylized bet over the ambiguous process of the stochastic variable $x$. We are later interested in a comparative static analysis for different realisations of ambiguity $a$.

Government. Let the government be a benevolent planner. It can borrow from international investors in the form of one-period discount bonds, denoted by $B_{t}>0$. Given limitations of 
private households to save or access international financial markets for consumption smoothing, the government provides an optimal tax- and transfer schedule that smooths private consumption, which are given by

$$
\begin{aligned}
& \tau_{0}=q_{0} B_{1}-B_{0}, \\
& \tau_{1}=-B_{1} .
\end{aligned}
$$

The government enters the period $t=0$ with the previously accumulated stock of debt $B_{0}$. Importantly, the government cannot commit to repay the debt when it becomes due in period $t$, but takes an optimal default decision. Default is a binary choice, denoted by $\delta_{t} \in\{0,1\}$, with a recovery value of zero. When defaulting, the government suffers from an exogenous penalty, which comes in the form of a loss on aggregate output:

$$
y^{\text {def }}=\left\{\begin{array}{l}
g F\left(z_{t}, l\right) \quad \text { if } \quad z_{t}=z^{h} \\
F\left(z_{t}, l\right) \quad \text { if } \quad z_{t}=z^{l}
\end{array}\right.
$$

Note that the penalty function with $g<1$ is pro-cyclical, since there is no penalty at low productivity states. As a result, default becomes optimal in a recession, thereby replicating the main feature of more complex penalty functions used in the sovereign debt literature (Arellano, 2008), or endogenous output costs (Engler and Große Steffen, 2016).

\subsection{Consumption-based asset pricing}

This section describes how international investors price government debt in the model. We extend the standard asset pricing model as e.g. in Samuelson (1969) in two directions, habit persistence in consumption and ambiguity aversion.

First, regarding habit persistence in consumption, we follow Brunnermeier and Nagel (2008) with their specification of constant external habit persistence parameter $h .^{9}$ Including this approach to habit in the constant relative risk aversion (CRRA) utility function yields time

\footnotetext{
${ }^{9}$ We think that time-varying habit persistence in the form of the difference between current and past aggregate consumption as in Campbell and Cochrane (1999) would be an interesting extension to the setup, which we leave for future work.
} 
variation in risk aversion through non time separability of preferences. ${ }^{10}$

Second, we account for ambiguity aversion through the maxmin model proposed by Gilboa and Schmeidler (1989). To focus on the main mechanism, we assume that only investors are ambiguity averse, which implies that households and the government are ambiguity neutral. Be reminded that investors, confronted with the fact that the support of the uniform distribution of the random variable $x$ determining the level of productivity in period $t=1$ is ambiguous, exhibit a set of multiple-priors regarding the support of the distribution which is determined by an exogenous realisation of ambiguity (a), as shown in equation (1). We denote expectations under the multiple priors model by $E_{t}^{p}$. Importantly, these expectations are jointly given by an agent's set of prior beliefs and her attitude toward ambiguity.

In order to discuss the differences between an ambiguity averse investor and the case without ambiguity, let us further define the operator $E_{t}$ as the expectation under the assumption that the investor is ambiguity neutral. In the Gilboa-Schmeidler model of ambiguity aversion, this can be compared to a situation where the level of realized uncertainty is zero, $a=0 .{ }^{11}$ This case is typically understood as the standard assumption in the subjective expected utility paradigm. Therefore, we use it as a useful benchmark to illustrate the effects ambiguity aversion in the model.

International investors make a consumption-savings decision as well as an investment decision. There is no background income to investors such that terminal period level of wealth determines consumption. Investments can be directed toward a riskfree asset with a certain payoff of one unit of the numeraire good in the next period. Alternatively, investors can purchase government debt which pays out one good in case the government does not default. In case of debt repudiation, the asset has a recovery value of zero.

Denote by $\alpha_{f}, \alpha_{b}$ the fraction of savings invested in the riskfree asset and government debt,

\footnotetext{
${ }^{10}$ There are alternative approaches to modeling habit persistence in the literature. In Abel (1990; 1999), utility is redefined as $u\left(c / h_{t}\right)$, which yields constant degree of risk aversion and, hence, not the desired properties for our analysis.

${ }^{11}$ In a dynamic framework with more than two periods, subjective expected utility would require more, specifically that also future realisations of ambiguity are zero.
} 
respectively. We can then write the investor's optimization problem as

$$
\begin{aligned}
& \max _{\left\{c_{0}, \alpha^{f}, \alpha^{b}\right\}} \min _{\left\{\operatorname{supp}^{p}(\mathcal{U} \in \mathcal{P})\right\}} E_{t}^{p} \sum_{t=0}^{T=1} \beta^{t} u\left(c_{t}, h\right) \\
& \text { s.t. } \quad W_{t+1}=\left(1-\delta_{t+1}\right)\left(W_{t}-c_{t}\right)\left[\alpha_{f} R_{t}^{f}+\alpha_{b} R_{t}\right]+\delta_{t+1}\left(W_{t}-c_{t}\right) \alpha_{f} R_{t}^{f} \\
& \alpha_{f}+\alpha_{b}=1
\end{aligned}
$$

where $\beta$ is the investor's discount factor and $R_{t}^{f}, R_{t}$ denote the returns on the riskfree asset and government debt, respectively. Initial investor's wealth is given by the pre-determined portfolio $W_{0}=\left(1-\delta_{0}\right) B_{0}+S_{0}$, where $S_{0}, B_{0}$ denote the volume of riskfree assets and government bonds due in period $t=0$.

Substituting the intertemporal budget constraint (4) into the optimization problem (3), the first-order conditions are

$$
\begin{gathered}
u^{\prime}\left(c_{t}, h\right)-\min _{\left\{\operatorname{supp}^{p}(\mathcal{U} \in \mathcal{P})\right\}} E_{t}^{p} \beta\left[u^{\prime}\left(c_{t+1}, h\right)\left(\alpha_{f} R_{t}^{f}+\left(1-\delta_{t+1}\right) \alpha_{b} R_{t}\right)\right]=0, \\
\min _{\left\{\operatorname{supp}^{p}(\mathcal{U} \in \mathcal{P})\right\}} E_{t}^{p} \beta\left[u^{\prime}\left(c_{t+1}, h\right) R_{t}^{f}\right]-\lambda=0, \\
\min _{\left\{\operatorname{supp}^{p}(\mathcal{U} \in \mathcal{P})\right\}} E_{t}^{p} \beta\left[u^{\prime}\left(c_{t+1}, h\right)\left(1-\delta_{t+1}\right) R_{t}\right]-\lambda=0,
\end{gathered}
$$

where $\lambda$ is the Lagrange multiplier on the portfolio constraint (5). The first equation reflects the optimal consumption-savings decision. It states that marginal utility today needs to equal the expected returns from the portfolio weighted by marginal utility tomorrow and the discount factor. Next, substituting first (7) and (8) into (6) yields $u^{\prime}\left(c_{t}, h\right)=\lambda$. Using this result, we obtain the asset pricing conditions

$$
\begin{aligned}
q_{t}^{f} & =\min _{\left\{\operatorname{supp}^{p}(\mathcal{U} \in \mathcal{P})\right\}} E_{t}^{p} \beta\left[\frac{u^{\prime}\left(c_{t+1}, h\right)}{u^{\prime}\left(c_{t}, h\right)}\right], \\
q_{t} & =\min _{\left\{\operatorname{supp}^{p}(\mathcal{U} \in \mathcal{P})\right\}} E_{t}^{p} \beta\left[\frac{u^{\prime}\left(c_{t+1}, h\right)}{u^{\prime}\left(c_{t}, h\right)}\left(1-\delta_{t+1}\right)\right],
\end{aligned}
$$

where we used the conventional relationship between gross returns and asset prices according to $R_{t}^{f}=1 / q_{t}^{f}$ and $R_{t}=1 / q_{t}$. In line with the literature on optimal sovereign default, we assume further that the return for riskfree assets is exogenously given by $R^{f}$. This is in line with the 
assumption of a small open economy and implies that the riskfree asset is in infinite supply.

Given the default incentives in the model that are fully described by the pro-cyclical penalty function, worst case expectations for repayment can be derived from (2) as ${ }^{12}$

$$
E_{t}^{p}\left[1-\delta_{t+1}\right]=\operatorname{Prob}^{p}\left\{z_{1}=z^{h}\right\}=1-\frac{\bar{x}-x_{l b}^{p}}{x_{u b}^{p}-x_{l b}^{p}} .
$$

Finally, market clearing on for government bonds requires that the amount of risky asset purchases by investors are equal to the market value of issued government debt:

$$
\alpha_{b}\left(W_{t}-c_{t}\right)=q_{t} B_{t+1}
$$

Definition. The models equilibrium is given by

1. Government policies given by optimal taxation and borrowing decisions $\left(\tau_{0}, \tau_{1}, B_{1}\right)$, as well as default decisions $\left(\delta_{0}, \delta_{1}\right)$ that maximize household utility $v\left(c_{0}^{h}, c_{1}^{h}\right)$, while taking as given the initial stock of accumulated government debt $B_{0}$;

2. Investors' decisions that yield an optimal consumption-savings decision $\left(c_{0}\right)$ and portfolio choices $\left(\alpha_{f}, \alpha_{b}\right)$ according to the investor's problem, while taking as given the riskfree return $R^{f}$, as well as the amount of initial wealth $W_{0}$, habit $h$, and ambiguity $a$;

3. Market clearing for government debt.

\subsection{Interaction of uncertainty with risk aversion}

In order to disentangle the effects of risk and ambiguity on the pricing of sovereign debt in (10), let us define the covariance evaluated under the worst case prior as

$$
\operatorname{cov}^{p}\left(u^{\prime}\left(c_{t+1}, h\right),\left(1-\delta_{t+1}\right)\right) \equiv E_{t}^{p}\left[u^{\prime}\left(c_{t+1}, h\right)\left(1-\delta_{t+1}\right)\right]-E_{t}^{p}\left[u^{\prime}\left(c_{t+1}, h\right)\right] E_{t}^{p}\left[1-\delta_{t+1}\right]
$$

Here, we loosely follow Epstein and Schneider (2010), who show that in the classic meanvariance portfolio choice problem, ambiguity averse investors consider ambiguity in the covariance matrix of assets for their decision. Using the definition of the covariance under ambiguity

\footnotetext{
${ }^{12}$ Note that ambiguity aversion is captured by non-additive probabilities, hence $\operatorname{Prob}^{p}\left\{z_{1}=z^{h}\right\}+$ $\operatorname{Prob}^{p}\left\{z_{1}=z^{l}\right\} \leq 1$ (Dow and Werlang, 1992).
} 
and dropping the minimization operator to simplify the notation, we can rewrite the asset pricing condition for government debt as

$$
q_{t}=\beta \frac{\operatorname{cov}^{p}\left[u^{\prime}\left(c_{t+1}, h\right),\left(1-\delta_{t+1}\right)\right]}{u\left(c_{t}, h\right)}+\beta \frac{E_{t}^{p}\left[u^{\prime}\left(c_{t+1}, h\right)\right] E_{t}^{p}\left[1-\delta_{t+1}\right]}{u^{\prime}\left(c_{t}, h\right)}
$$

Finally, substituting in the definition of the riskfree rate, the bond pricing condition takes the following form

$$
q_{t}=q_{t}^{f}\left(1-E_{t}^{p}\left[\delta_{t+1}\right]\right)+\beta \frac{\operatorname{cov}^{p}\left[u^{\prime}\left(c_{t+1}, h\right),\left(1-\delta_{t+1}\right)\right]}{u^{\prime}\left(c_{t}, h\right)} .
$$

The first term in the asset pricing condition for government bonds (12) captures the first-order effect of uncertainty for the pricing decision of ambiguity averse international investors, as it is first described in (Epstein and Wang, 1994). Higher ambiguity leads to a more pessimistic worst case prior, hence to a higher default expectation $E_{t}^{p}\left[\delta_{t+1}\right]$ (Große Steffen, 2015).

The second term of condition (12) takes center stage for the present analysis. It contains a risk-premium that is negative and depends on investors' coefficient of relative risk aversion. To analyse this in more detail, let investors' preferences be given by CRRA utility with habit formation, as discussed before, hence

$$
u\left(c_{t}, h\right)=\frac{\left(c_{t}-h\right)^{1-\gamma}}{1-\gamma}
$$

In this framework, it is useful to define the surplus consumption ratio of the investor as $\phi_{t} \equiv$ $\left(c_{t}-h\right) / c_{t}$ (Campbell and Cochrane, 1999). The coefficient of relative risk aversion is then given by

$$
\eta_{t} \equiv-\frac{c_{t} u_{c c}\left(c_{t}, h\right)}{u_{c}\left(c_{t}, h\right)}=\gamma \frac{c_{t}}{c_{t}-h}=\frac{\gamma}{\phi_{t}}
$$

which implies a constant coefficient of relative risk aversion $\gamma$ if habit is absent $(h=0)$.

Let us now return to the covariance term in (12). Intuitively, if default is expected to happen and $\left(1-\delta_{t+1}\right) \rightarrow 0$, then this affects negatively the wealth of the international investor in the consecutive period, $W_{t+1}$, along with her consumption level. This, in turn, pushes up 
the marginal utility for future consumption, $u^{\prime}\left(c_{t+1}, h\right)$, as excess consumption is falling, which leads to the conclusion that $\operatorname{cov}^{p}\left[u^{\prime}\left(c_{t+1}, h\right),\left(1-\delta_{t+1}\right)\right]<0 .{ }^{13}$

Further, condition (12) implies a second-order effect of ambiguity on the pricing of government debt that only arises when risk aversion and ambiguity aversion are jointly present in investor preferences. In particular, the covariance-term is affected by worst case prior beliefs about the repayment of government debt in the final settlement period, which render the covariance even more negative such that

$$
\operatorname{cov}^{p}\left(u^{\prime}\left(c_{t+1}, h\right),\left(1-\delta_{t+1}\right)\right) \leq \operatorname{cov}\left(u^{\prime}\left(c_{t+1}, h\right),\left(1-\delta_{t+1}\right)\right)<0
$$

To see this intuitively, note that the expected cash flow under the worst case prior is lower than under subjective expected utility due to the distorted probabilities, such that $E_{t}^{p}\left[1-\delta_{t+1}\right] \leq$ $E_{t}\left[1-\delta_{t+1}\right]$. Further, the expectation for marginal utility of consumption in the consecutive period is higher since investors act under the worst case prior as if default is more likely, such that $E_{t}^{p}\left[u^{\prime}\left(c_{t+1}, h\right)\right] \geq E_{t}\left[u\left(c_{t+1}, h\right)\right]$.

Next, we prove formally that the relationship in (15) holds. ${ }^{14}$ We thereby formalize that higher levels of ambiguity about the fundamental state lead in the maxmin model of ambiguity aversion to a higher coefficient of relative risk aversion, and thereby to time-variation in risk premia.

To show this, we build on the results provided by Cherbonnier and Gollier (2015). They find that decreasing aversion to risk in wealth is maintained in the maxmin model if and only if the utility function $u$ exhibits decreasing concavity. ${ }^{15}$ Further, the authors identify three conditions that guarantee that decreasing aversion also leads to higher demand for the risky asset conditional on higher wealth. ${ }^{16}$ These are preferences that feature (i) hyperbolic absolute

\footnotetext{
${ }^{13}$ As we know from the definition of the covariance, $\operatorname{cov}\left[u^{\prime}\left(c_{t+1}, h\right),\left(1-\delta_{t+1}\right)\right]=E_{t}\left[u^{\prime}\left(c_{t+1}, h\right)\left(1-\delta_{t+1}\right)\right]-E_{t}\left[u^{\prime}\left(c_{t+1}, h\right)\right] E_{t}\left[1-\delta_{t+1}\right]$.

For the covariance to exist, both its elements need to be stochastic variables. In fact, both arguments are dependent on the exogenous variable of the model, which is given by $z_{t+1}$, see Figure D.8.

${ }^{14}$ It was previously shown by Alary et al. (2013) that the introduction of ambiguity aversion raises the demand for self-insurance. A related finding was presented in Trojani and Vanini (2004) and Maenhout (2004) for the case of robust control preferences, but without a comparative static analysis for different levels of realized ambiguity. Such exogenous changes in ambiguity are typically not accommodated by the robust control framework.

${ }^{15}$ Specifically, see Proposition 1 in Cherbonnier and Gollier (2015).

${ }^{16}$ See Proposition 4 in Cherbonnier and Gollier (2015).
} 
risk aversion (HARA), (ii) decreasing concavity, and (iii) the coefficient of risk aversion is positive, thus $\gamma>0$.

The first two conditions are satisfied under the chosen framework of CRRA utility with external habit persistence in consumption. This can be seen from relative risk aversion in the model as defined in (14). The third condition is fulfilled if one assumes a risk averse investor, which requires $\gamma>0$ in the calibration. We are now able to state the main result regarding the interaction from ambiguity aversion and risk aversion in the model in the presence of timevarying levels of ambiguity in the following proposition:

Proposition 1. Suppose that investors are ambiguity averse according to the maxmin-model. Suppose further that utility is HARA and decreasing concave with a positive coefficient of risk aversion. Then, an increase in uncertainty from $a_{1}$ to $a_{2}$ with $a_{1}<a_{2}$ leads to higher risk aversion, thereby inducing time-variation in risk aversion.

Proof. We need to show that the following condition holds:

$$
-\frac{u^{\prime \prime}\left(E_{t}^{p}\left[W_{1} \mid a_{1}\right], h\right)}{u^{\prime}\left(E_{t}^{p}\left[W_{1} \mid a_{1}\right], h\right)} E_{t}^{p}\left[W_{1} \mid a_{1}\right]<-\frac{u^{\prime \prime}\left(E_{t}^{p}\left[W_{1} \mid a_{2}\right], h\right)}{u^{\prime}\left(E_{t}^{p}\left[W_{1} \mid a_{2}\right], h\right)} E_{t}^{p}\left[W_{1} \mid a_{2}\right]
$$

Using the notation of relative risk aversion from (14), this condition can be rewritten as

$$
E_{t}^{p}\left[\eta_{t+1} \mid a_{1}\right]=\frac{\gamma}{E_{t}^{p}\left[\phi_{t+1} \mid a_{1}\right]}<\frac{\gamma}{E_{t}^{p}\left[\phi_{t+1} \mid a_{2}\right]}=E_{t}^{p}\left[\eta_{t+1} \mid a_{2}\right]
$$

Given that expected surplus consumption under the worst case prior is decreasing in uncertainty, or $\partial E_{t}^{p}\left[\phi_{t+1}\right] / \partial a<0$, this condition is fulfilled, such that the following relationship holds:

$$
\frac{\partial E_{t}^{p}\left[\eta_{t+1}\right]}{\partial a}>0
$$

The content of Proposition 1 is illustrated in Figure 1(a). First, see the wealth of the investor in period $t=1$ under default and repayment $\left(W_{1, d}, W_{1, p a y}\right)$, along with the expected utility of the international investor. ${ }^{17}$ If ambiguity is positive $(a>0)$, then the investors' expected

\footnotetext{
${ }^{17} \mathrm{~A}$ further detailed illustration of each of these investors' characteristics is provided in the Appendix C.
} 
utility changes from $E_{t}\left[u\left(W_{1}\right)\right]$ to $E_{t}^{p}\left[u\left(W_{1}\right)\right]$. Due to the first-order effect of ambiguity through ambiguity aversion, expected utility is moving from point $A$ to point $B$. It is through the presence of habit persistence in consumption that introduces decreasing aversion such that this change in the level of ambiguity is accompanied by an increase in risk aversion of the investor.

In the next section, we provide a numerical example in order to give an illustration of the different effects that ambiguity and risk imply for the pricing of government debt.

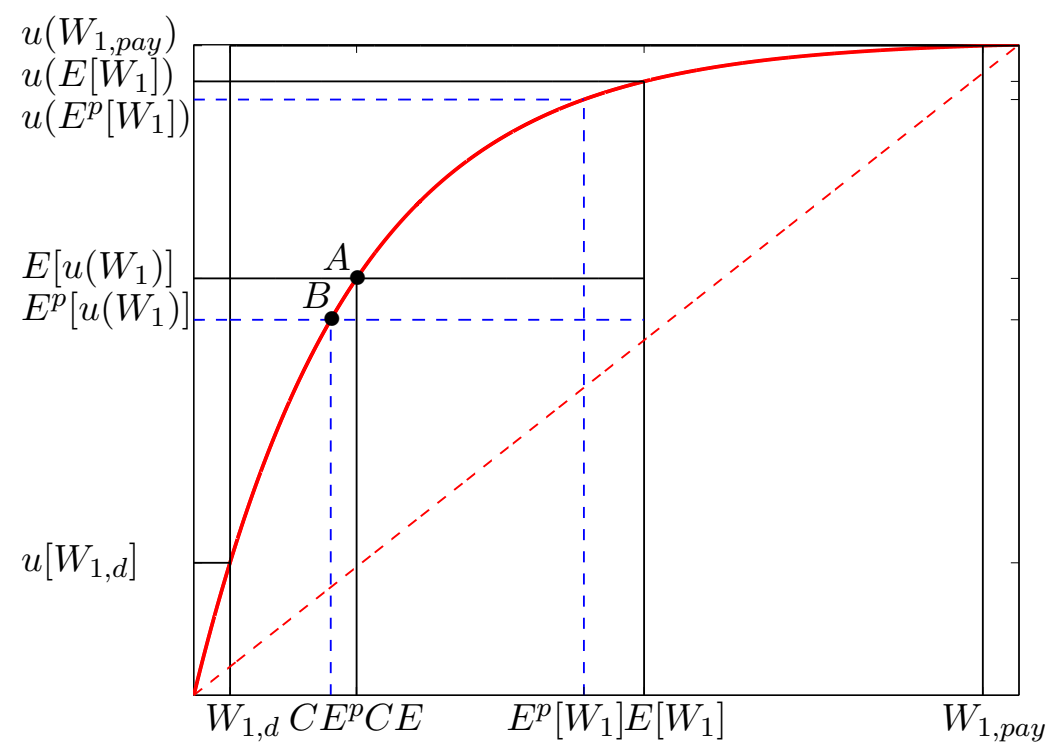

Figure 1: Effect of uncertainty on risk aversion

\subsection{Numerical illustration}

We further illustrate the different effects of risk aversion and ambiguity aversion by discussing the numerical results of the model. ${ }^{18}$ The results are presented in Figure 2.

First, we focus on the effect for net bond returns $\left(R_{t}-1\right)$ in Figure 2(a). The baseline result contains preferences as specified above, i.e. with ambiguity aversion, risk aversion and habit persistence in consumption. Note that there is a first-order effect from ambiguity by a shift in yields. This can be seen by comparing the bond pricing schedule by a risk neutral investor with the bond pricing schedule of an ambiguity averse, but risk neutral investor. Further, there is a second-order effect when risk aversion and habit persistence in consumption

\footnotetext{
${ }^{18}$ The numerical solution and calibration of the model are described in detail in Appendix A.
} 


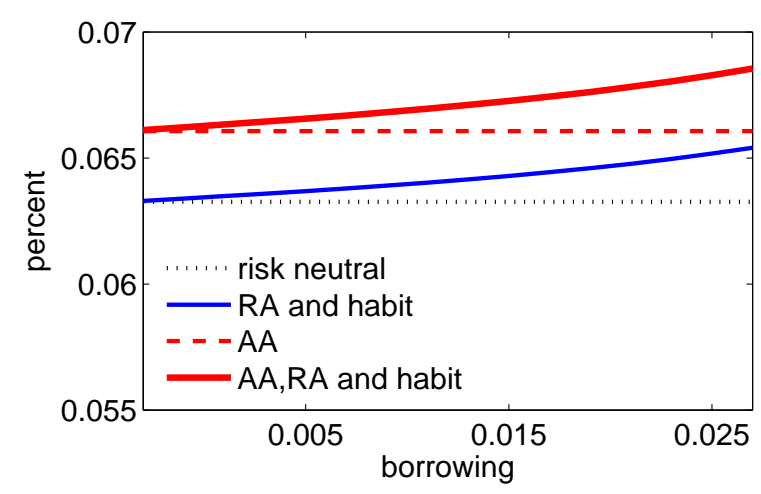

(a) Bond yields, $\left(R_{t}-1\right)$

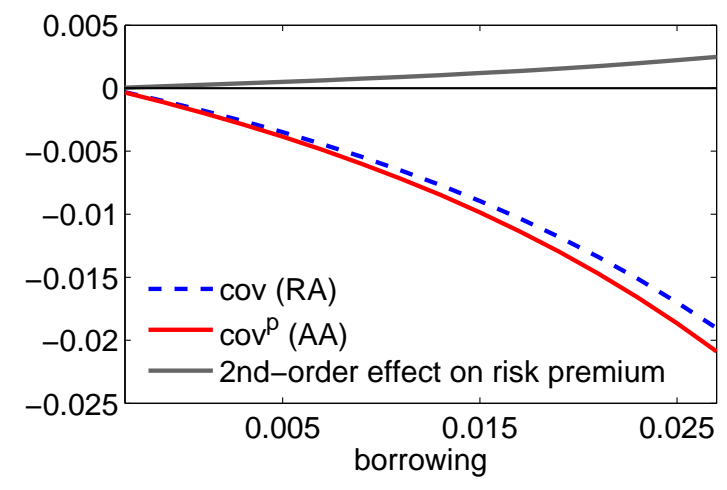

(c) Second-order effect of ambiguity

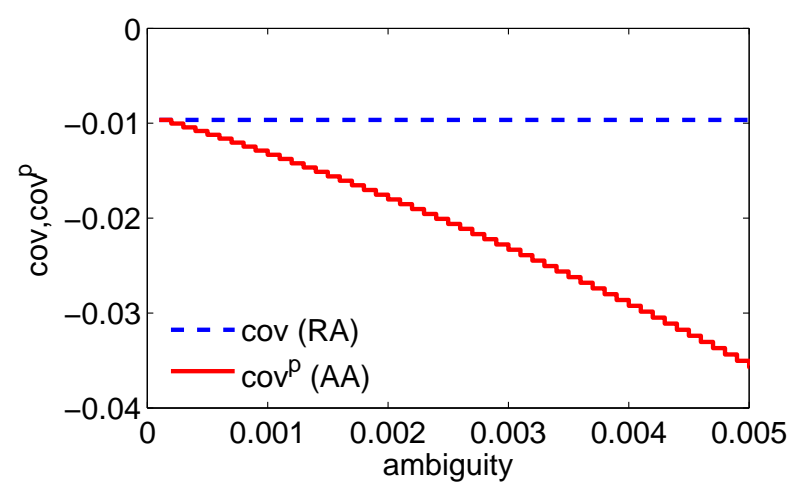

(b) Covariance under ambiguity

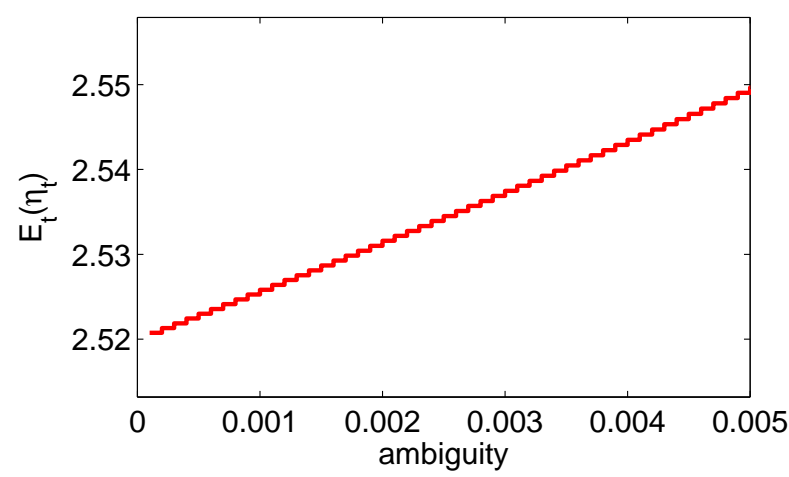

(d) Coefficient of risk aversion

Figure 2: Numerical model results

are introduced. Risk premia increase the more the government borrows from international investors, as the covariance turns more negative. The second-order differential effect of the joint presence of ambiguity aversion, risk aversion and habit persistence in consumption is further illustrated in Figure 2(c). When ambiguity aversion is introduced, the covariance turns more negative, as suggested by the result in condition (15), which leads to an additional rise in the risk premium. This effect is enforced when ambiguity increases. While the covariance under ambiguity neutrality remains unaffected by a rise in ambiguity, the covariance evaluated under the worst case prior turns more negative, as illustrated in Figure 2(b).

The intuition for this effect can be understood by considering the definition of relative risk aversion in expectation, $E_{t}^{p}\left[\eta_{t+1}\right]=\gamma /\left(E_{t}^{p}\left[\phi_{t+1}\right]\right)$. Through habit persistence in consumption, $\eta_{t+1}$ is inversely related to expected surplus consumption. If ambiguity rises, worst case expectations deteriorate such that investors become increasingly cautious about securing a subsistence level of consumption in the future period, which reduces investment in government bonds. As 
a result, the coefficient of relative risk aversion increases with ambiguity (Figure $2(\mathrm{~d})$ ).

\section{Empirical setup}

The remainder of the paper, building upon the model outlined above, is concerned with the empirical assessment of the effect of ambiguity on the pricing of sovereign debt. Let us rewrite equation (12) such that the decomposition in fundamental default risk, risk aversion and ambiguity on the sovereign bond price becomes more evident. We use the property that for positive values of uncertainty we always have $E_{t}\left[\delta_{t+1}\right]<E_{t}^{p}\left[\delta_{t+1}\right]$, where $E_{t}$ denotes the rational expectations operator of an ambiguity neutral investor, as discussed in the previous section. Expanding equation (10) with ambiguity neutral expectations, the asset pricing condition for risky and ambiguous government debt holding can be decomposed into four distinct components as

$q_{t}=q^{f}-\underbrace{\left(q^{f} E_{t}\left[\delta_{t+1}\right]\right)}_{\text {fund. def. risk }}+\underbrace{\frac{\beta}{u\left(c_{t}, h\right)} \operatorname{cov}(\cdot)}_{\text {risk prem. }}+\underbrace{\frac{\beta}{u\left(c_{t}, h\right)}\left\{\operatorname{cov}^{p}(\cdot)-\operatorname{cov}(\cdot)\right\}+q^{f}\left(E_{t}\left[\delta_{t+1}\right]-E_{t}^{p}\left[\delta_{t+1}\right]\right),(17}_{\text {ambiguity premium }}$

where $\operatorname{cov}(\cdot)=\operatorname{cov}\left(\lambda_{t+1},\left(1-\delta_{t+1}\right)\right)$ and $\operatorname{cov}^{p}(\cdot)=\operatorname{cov}^{p}\left(\lambda_{t+1},\left(1-\delta_{t+1}\right)\right)$. Equation (17) is our point of departure for taking the model to the data. Note that the bond price is inversely related to the yield and that the model implies financing premia to increase in fundamental default risk, risk aversion, and ambiguity.

In the empirical analysis we proxy for ambiguity with a measure of economic uncertainty (discussed in detail below), given the lack of an empirical measure of economic ambiguity at the macro level. The literature on economic uncertainty typically uses the notion of uncertainty as a stand-in for both, ambiguity or Knightian uncertainty ${ }^{19}$ and risk (Bloom, 2014). While Ilut and Schneider (2014) use forecast dispersion among professional forecasters to proxy for ambiguity, we construct a high-frequency uncertainty measure based on forecast errors adopting the approach by Jurado et al. (2015), who argue that forecast errors may well be driven by Knightian uncertainty. In what follows, we use the notion of uncertainty as an empirical proxy

\footnotetext{
${ }^{19}$ Knightian uncertainty (Knight, 1921) refers to situations where the probability distribution itself is unknown to the economic agent and hence is equivalent to the concept of ambiguity used in Section 3
} 
for the concept of ambiguity used in the theoretical model in Section 3.

We make use of a trivariate Markov-switching in heteroscedasticity vector autoregressive model (MSH-VAR) containing a measure of the sovereign financing premium as well as measures of aggregate risk aversion and macroeconomic uncertainty and model the sovereign yield to be driven by the three (unobservable) terms in equation (17): a fundamental default risk shock, a risk aversion shock and an uncertainty shock. Finally, we decompose the sovereign financing premium requested by market participants into contributions from these three shocks. In addition we use the model to evaluate the response of the measure of risk aversion to an uncertainty shock as an empirical assessment of the validity of Proposition 1.

The choice of model has the advantage of allowing to make use of the statistical properties of the data in order to identify the shocks of interest following the identification procedure pioneered by Rigobon (2003). In the context of VAR models, the properties of the data allow for the identification of orthogonal structural shocks within the model under certain conditions (Lanne and Lütkepohl, 2008). Making use of the statistical properties of the data for identification of orthogonal shocks is particularly helpful as economic theory does not provide a set of restrictions — neither exclusion restrictions on the short or long run effects matrix nor more agnostic sign, shape or magnitude restrictions - that would enable us to disentangle the three shocks of interest: a fundamental default risk shock, a risk aversion shock, and a macroeconomic uncertainty shock.

While the statistical properties of the data help to uncover orthogonal shocks that are unique up to sign and column rotations from the model, they do not deliver any labeling of the shocks that would make them economically interpretable. Based on the assumption that the identification approach provides a vector of economic shocks, our strategy to label the set of shocks is twofold. Firstly, we draw on the information contained in the forecast error variance decomposition: The shocks explaining most of the variance in the risk aversion and the uncertainty measure are labeled risk aversion shock and uncertainty shock, respectively. The remaining shock, expected to dominate the variation in the financing premium, is labeled the fundamental default risk shock. Secondly, in order to further back the economic interpretation of the shocks we follow the more narrative approach by Rigobon (2003) and exploit patterns in the series of the structural shocks uncovered from the MSH-SVAR model for a consistency 
check of the labeling. The two subsequent sections discuss details of the construction of the uncertainty index and the remainder of the data set as well as the specification of the MSHSVAR in further detail before turning to the results.

\section{Data}

This section provides an overview of the data used in the subsequent analysis. It discusses in greater detail the construction of the uncertainty index and the measure of aggregate risk aversion, as well as describes the vector of exogenous variables - mainly related to unconventional monetary policy action — that are controlled for in the empirical analysis.

The vector of endogenous variables consists of a proxy for the sovereign financing premium, a measure of aggregate risk aversion, and an uncertainty proxy. The analysis covers Italy and Spain, two countries that exhibited a particularly strong deterioration in their sovereign financing conditions throughout the financial and sovereign debt crisis. Neither received any financial assistance from the European Financial Stabilization Mechanism (EFSM) or its successor, the European Stability Mechanism, that could potentially distort the estimation of the effect running from the ambiguity in the economy to the pricing of sovereign debt, discussed in Section 3. Limited by the availability of data, the sample spans from 2004 to $2015{ }^{20}$ We use data of weekly frequency in order to average out noise in higher frequency, for example daily data, and to make the estimation of the model computationally feasible. Figure D.11 in the Appendix D plots the endogenous variables in the VAR model explained in detail below.

We proxy for the sovereign financing premium with credit default swaps (CDS), following Aizenman et al. (2013). CDS, usually traded over-the-counter, are derivatives that function similar to credit insurances. The seller of a CDS insures the buyer against the default of the creditor such that the price of CDS mirrors the financing premium of the underlying asset over a safe asset. The advantage of using CDS rather than yield spreads on sovereign bonds is that the CDS markets usually are more liquid and, hence, deliver more accurate measures of financing premia (Longstaff et al., 2011). Fontana and Scheicher (2010) find that price discovery for

\footnotetext{
${ }^{20}$ The limiting factor is the availability of sovereign credit defaults swaps data at weekly frequency. The sample spans from 01/12/2004 for Italy and 04/12/2004 for Spain to 04/20/2015 and includes 589 (Italy) and 576 (Spain) weekly observations.
} 
Spanish and Italian sovereign debt actually takes place in the sovereign CDS markets rather than in sovereign bond markets during the financial crisis. We obtain sovereign CDS data for Spain and Italy at five year maturity from Bloomberg.

\subsection{A high frequency measure of macroeconomic uncertainty}

In the construction of a measure of economic uncertainty, we face two main challenges. Firstly, the empirical model relies on the identification of different volatility regimes, which requires sufficient number of observations. As we aim at decomposing sovereign financing premia over the course of the recent period of fiscal stress, there is a natural limit to the number of available observations. A solution is to aim for a high frequency measure. Secondly, as the concept of Knightian uncertainty implemented in the theoretical model in Section 3 refers to the production outlook specific to the economy, the measure should be country specific and talk about the uncertainty of the production outlook.

In order to construct a high frequency, country specific measure of economic uncertainty we follow the approach proposed by Jurado et al. (2015). ${ }^{21}$ They extract an uncertainty proxy at monthly frequency from a large dataset of macroeconomic variables by determining the common variation in the unforcastable component of those data. Their procedure involves three steps. In a first step forecast errors are obtained based on conditional mean forecasts from factor augmented autoregressive models. In a second step stochastic volatility in the forecast errors allows the extraction of uncertainty of variable $y_{j}$ at time $t$ for horizon $h$ of a single series, which is defined by

$$
\mathcal{U}_{j, t}^{y}(h) \equiv \sqrt{E\left\{\left[y_{j t+h}-E\left(y_{j, t+h} \mid I_{t}\right)\right]^{2} \mid I_{t}\right\}},
$$

where $I_{t}$ denotes the information available at time $t$. A crucial assumption in their setup is that every series in the dataset features time varying volatility, which generates the time variance in uncertainty. In a third step the uncertainty estimates for the single variables in the dataset are aggregated to an economy-wide index of uncertainty. Appendix B provides a more detailed description of the construction of the uncertainty index in Jurado et al. (2015).

\footnotetext{
${ }^{21}$ Alternative measures, such as the disagreement or subjective uncertainty of professional forecasters would be other natural candidates to proxy for ambiguity with regards to the production outlook, but are only available at lower, that is, monthly frequency.
} 
As we are aiming at a higher frequency, we depart from their approach in the use of the underlying dataset and apply their methodology to a large dataset of equity returns in order to construct a country specific high frequency measure of economic uncertainty. ${ }^{22}$ The construction of the fundamental macroeconomic uncertainty measure builds upon a large set of weekly equity return data (total return index) from Thomson Reuters Datastream covering 1492 equity return index series for Spain and 1928 for Italy. ${ }^{23}$ This dataset contains many degenerate series, as certain stocks are not traded continuously or traded only for a short period within the sample. We therefore remove all series that are either not traded or not present in the market for more than one third of the sample. In addition we control for equity splits and other outliers by removing observations associated with changes in the index above four standard deviations. After cleaning the dataset and filling the remaining gaps by means of a dynamic factor model along the lines of Schumacher and Breitung (2008), the dataset compiles 201 and 543 equity return series for Spain and Italy, respectively.

The high frequency measures of economic uncertainty for Spain and Italy for the period from 1990 to 2015 are plotted in Figure 3. The figure also provides an interpretation regarding the events underlying a peak in the economic uncertainty. Both indexes clearly indicate their largest peaks in economic uncertainty around the most recent financial crisis in the years 2008 and 2009, but also around the Asian and Russian crises around 1998, while for Italy the rise in uncertainty surrounding the sovereign debt crisis 2011/2012 is more pronounced than for Spain. Economic uncertainty in both countries seems to be driven by the same global or regional events, with a few exceptions, among them the Madrid train bombings of 2004.

Figure D.10 in the Appendix D plots the high frequency uncertainty measures for Spain and Italy against stock market volatilities and the low frequency macroeconomic uncertainty measures based on monthly macroeconomic data. This type of comparison is particularly informative as we deploy similar data as the former and the same methodology as the latter.

\footnotetext{
${ }^{22}$ Jurado et al. (2015) argue that the construction of an uncertainty measure for macroeconomic data needs to take into account the forecastable component in macroeconomic data and deploy diffusion index forecasts for this purpose. Accounting for the forecastable component in equity returns may seem less urgent, given that equity returns are harder to forecast than macroeconomic time series. However, Ludvigson and Ng (2007) document that diffusion index models, as the one used in the construction of forecast errors here, provide forecasts for equity returns that are superior to using simple historical averages.

${ }^{23}$ The total return index is a better measure of the performance of a stock and its underlying company in that it includes not only the capital gain on the stock, but also returns related to dividend payments, the value of rights issues, special dividends, and stock dilutions.
} 


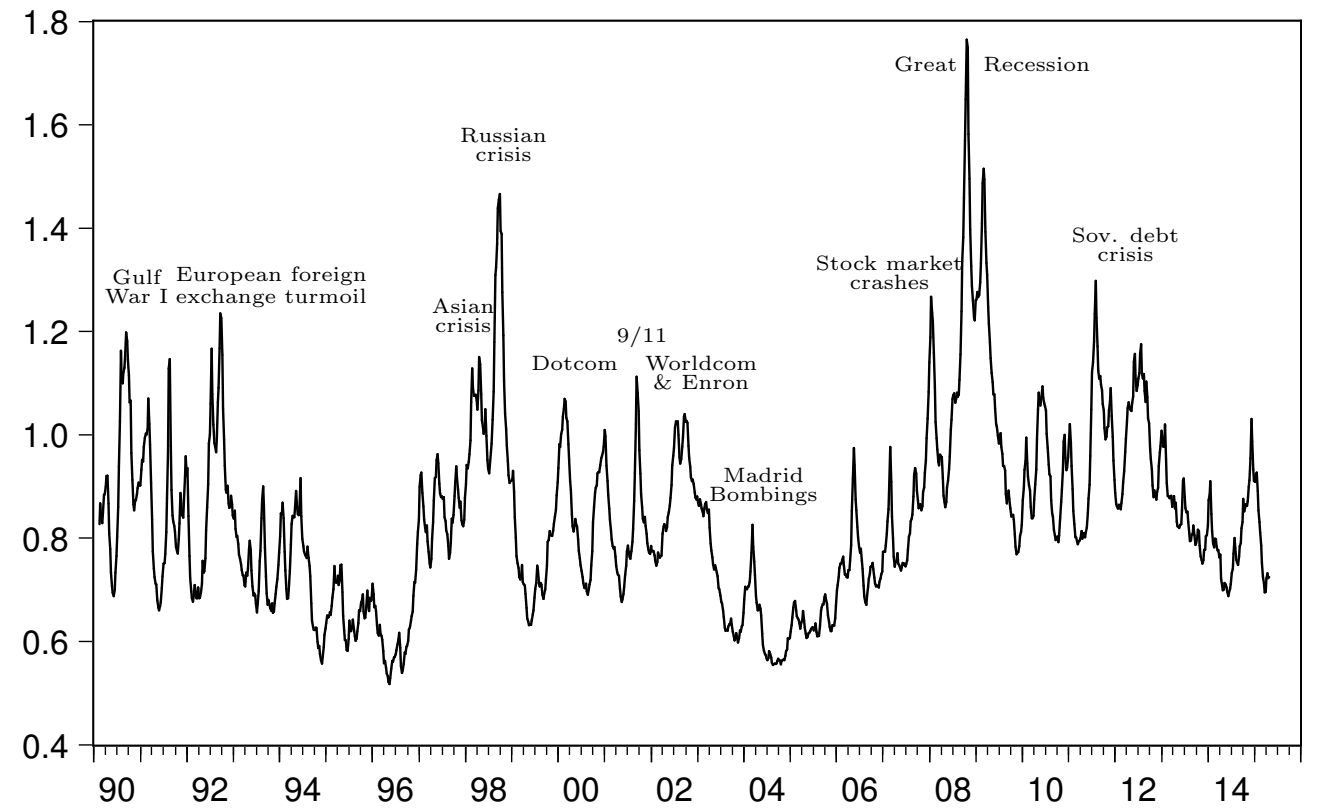

(a) Spain

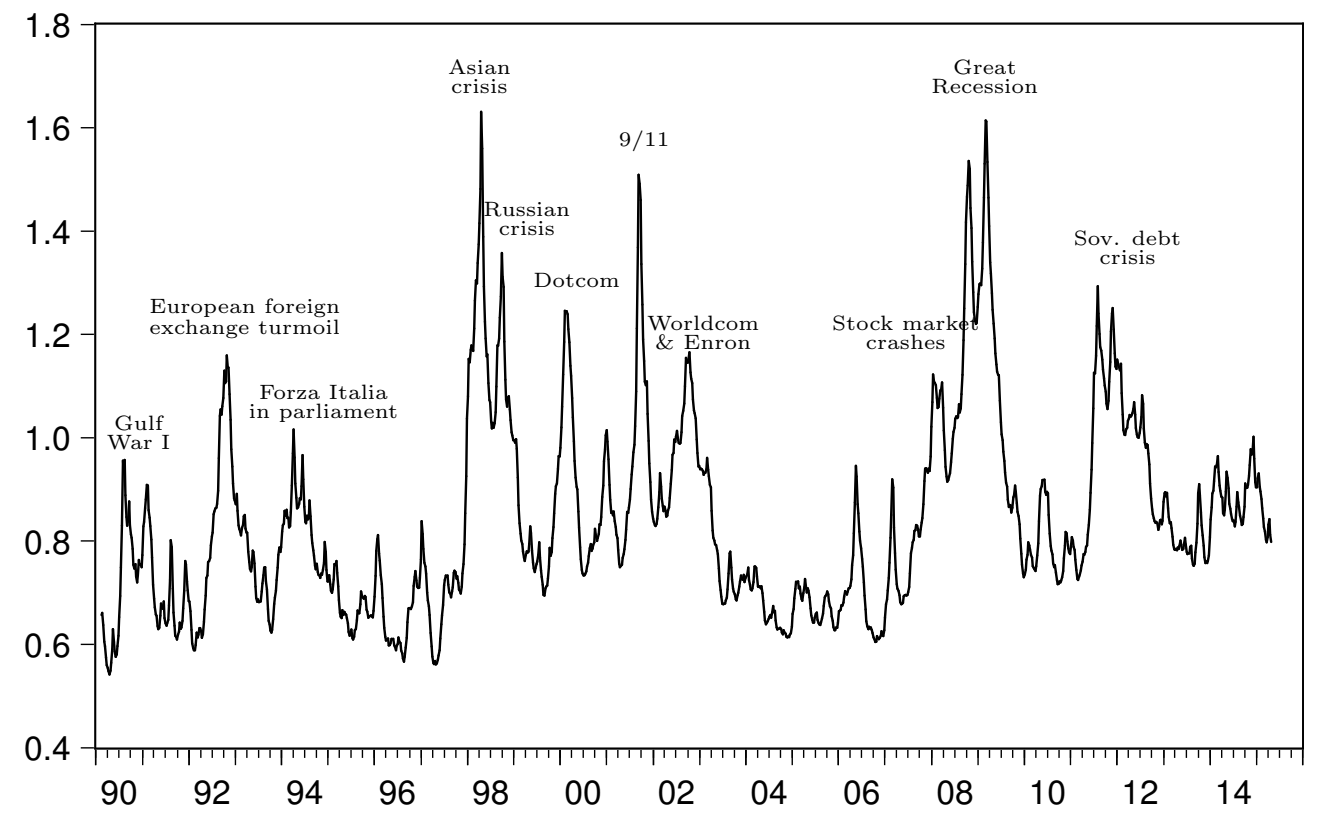

(b) Italy

Figure 3: Weekly uncertainty index based on the method by Jurado et al. (2015) applied to a large dataset of equity returns. 
While the stock market volatility exhibits numerous large and significant jumps throughout the sample, but low persistence, the low frequency macroeconomic uncertainty peaks only once significantly at the onset of the financial crisis and is quite persistent. The measure proposed here, resembles those properties rather well, although it is constructed based on equity data: It features much stronger persistence than the stock market volatility and exhibits two significant peaks, the larger one at the onset of the financial crisis in late 2008 and one during the unfolding of the sovereign debt crisis in 2011.

Table 1 compares the constructed high frequency measure of macroeconomic uncertainty (aggregated to monthly frequency) to a number of alternative indicators of economic uncertainty at lower frequencies, that is, to (1) a measure of the degree of disagreement of professional forecasters, ${ }^{24}(2)$ a low frequency macro data uncertainty index that we construct from a set of 51 monthly macro series for Spain and 84 monthly macro series for Italy; and (3) the news based policy uncertainty index provided by Baker et al. (2013) and weekly realized stock market volatility. ${ }^{25}$ The aggregated high frequency measures correlate significantly with the set of alternative measures at lower frequency and the realized stock market volatility. The lowest correlation is found with the policy uncertainty measure. As it aims at capturing a somewhat different concept of uncertainty related to political decision processes, the lower correlation seems plausible and expected.

Table 1: Correlation of our uncertainty measure with alternative measures

\begin{tabular}{lcccl}
\hline & Spain & Italy & frequency & sample \\
\hline Forecast Disagreement & $0.46^{* * *}$ & $0.33^{* * *}$ & monthly & 2007M01-2014M08 \\
Uncertainty based on monthly macro data & $0.37^{* * *}$ & $0.46^{* * *}$ & monthly & $1990 \mathrm{M} 07-2015 \mathrm{M} 05$ \\
Policy uncertainty index (Baker et al., 2013) & $0.27^{* * *}$ & $0.33^{* * *}$ & monthly & $1997 / 2001 \mathrm{M} 1-2015 \mathrm{M} 05$ \\
Realized stock market volatility & $0.65^{* * *}$ & $0.66^{* * *}$ & weekly & $2000 \mathrm{~W} 1-2015 \mathrm{~W} 19$ \\
\hline Uncertainty measure (Spain) & 1 & $0.81^{* * *}$ & monthly & $1990 \mathrm{M} 02-2015 \mathrm{M} 05$ \\
\hline
\end{tabular}

Notes: The weekly uncertainty measure based on equity returns is aggregated to monthly frequency where necessary for comparison. ${ }^{* * *}$ Indicates significance at the 1 percent level.

The validity of the constructed measure as a high frequency indicator of macroeconomic

\footnotetext{
${ }^{24}$ Forecast disagreement captures the interdecile range of the distribution of point forecasts over GDP growth provided by a panel of professional forecasters, where the data is taken from Consensus Economics and Focus Economics.

${ }^{25}$ Realized stock market volatility is taken from the Oxford-Man Institute's 'realized library' and aggregated to weekly frequency by averaging.
} 
uncertainty critically depends on the closeness of the link between equity markets and the real economy. We argue that under the assumption of efficient markets our equity based measure of economic uncertainty reflects the fundamental macroeconomic uncertainty in the economies, for investors, entrepreneurs, employees and other stakeholders of the considered companies alike.

Overall we take the strong and significant correlation among our high frequency uncertainty measure and alternative uncertainty measures together with the evidence from the graphical comparison in Figure D.10 as reassuring in that we well capture economic uncertainty at weekly frequency.

\subsection{A measure of risk aversion}

In order to construct a measure of risk aversion of (international) investors, we borrow from the recent literature that computes the variance premium from options implied volatility indexes (Bollerslev et al., 2009, 2011; Bekaert et al., 2013; Bekaert and Hoerova, 2014). Option implied volatility indexes, for example, the CBOE volatility index (VIX), may be decomposed into one part capturing expected market volatility and a second part capturing risk aversion. We make use of such a decomposition in order to obtain a proxy for the risk aversion of international investors, as discussed in the model framework in Section 3. We base our measure of global risk aversion on the VIX, the options implied volatility index of the S\&P500. We follow Bekaert et al. (2013) in constructing forecasts for the realized volatility based on a linear model incorporating the squared VIX and the past realized variance as predictors. ${ }^{26}$ As in Bekaert et al. (2013), we winsorize the data prior to the estimation. ${ }^{27}$ The difference between the squared VIX and the estimated conditional variance constitutes the proxy for risk aversion among international investors.

\footnotetext{
${ }^{26}$ The data on realized variances for five minute windows is taken from the Oxford-Man Institute's 'realized library'.

${ }^{27}$ Winsorization eliminates outliers in the distribution by replacing values in the tails with those of the respective percentiles. The underlying data, that is the VIX and realized stock market volatility, are winsorized at the one percent level.
} 


\subsection{Exogenous controls}

The vector of exogenous control variables in the MSH-VAR model contains the short term US nominal interest rate in order to control for global opportunity costs, bid-ask spreads controlling for time varying liquidity premia and a range of non-standard monetary policy measures, as we want to make sure our estimates are not affected by the extraordinary monetary policy action taken during the sample period. The monetary policy measures include dummy variables for the announcements of the Securities Markets Programme (SMP), the Long Term Refinancing Operations (LTROs) and the Outright Monetary Transactions (OMT) as well as variables capturing the volumes of their implementation ${ }^{28}$. The CDS Bid-Ask Spread is computed from bid and ask prices according to the formula spread $=\frac{p^{a s k}-p^{b i d}}{\left(p^{a s k}+p^{b i d}\right) / 2}$. Sources are Thomson Reuters Datastream, the ECB for data on unconventional monetary policy, and Bloomberg for the CDS prices, the bid-ask spreads are based upon.

\section{The MSH-SVAR}

The reduced form VAR model used for the empirical analysis is described by

$$
y_{t}=\nu+A_{1} y_{t-1}+A_{2} y_{t-2}+\cdots+A_{p} y_{t-p}+\Gamma_{0} x_{t}+\Gamma_{1} x_{t-1}+\cdots+\Gamma_{n} x_{t-n}+\Xi d_{t}+u_{t}
$$

where $y_{t}$ is the vector of $K$ endogenous variables, $x_{t}$ contains the $N$ exogenous variables and $A_{i}$ 's and $\Gamma_{j}$ 's are matrices that hold the respective coefficients with $i=1, \ldots, p$ and $j=1, \ldots, n . \nu$ is a vector of constant terms and $d_{t}$ holds the $L$ dummy variables with $\Xi$ being its respective coefficient matrix. $u_{t}$ represents the vector of reduced form error terms with $E\left[u_{t}\right]=0$ and $E\left[u_{t} u_{t}^{\prime}\right]=\Sigma_{u}\left(S_{t}\right)$. In addition we assume that the conditional distribution of $u_{t}$ is normal, hence, $u_{t} \mid S_{t} \sim \mathrm{N}\left(0, \Sigma_{u}\left(S_{t}\right)\right)$, that is, following Lanne et al. (2010) and Lütkepohl and Netšunajev (2014) the distribution of the reduced form error term is assumed to depend on a discrete Markov process $S_{t}$ that can take on $M$ values representing different regimes, $S_{t} \in\{1, \ldots, M\}$. While the model allows for Markov switching in the covariance of the residuals the parameters governing the first moments of the model are restricted to be constant over the sample.

\footnotetext{
${ }^{28}$ We include volumes for the SMP and LTROs with 6-12 and 36 months maturity as additional exogenous variables.
} 
The uncorrelated structural shocks, given by $\varepsilon$, map into the reduced form residuals as

$$
u_{t}=B \varepsilon_{t},
$$

via the matrix $B$ of impact effects (see Lütkepohl, 2005, Chapter 9). Since the distribution of the residuals is governed by a Markov process, we have $\operatorname{var}\left(u_{t} \mid S_{t}\right)=\Sigma_{u}\left(S_{t}\right)=B \Lambda\left(S_{t}\right) B^{\prime}$ with $E\left[\varepsilon_{t}\right]=0$ and $E\left[\varepsilon_{t} \varepsilon_{t}^{\prime}\right]=\Lambda\left(S_{t}\right) . \Lambda\left(S_{t}\right)$ is a diagonal matrix satisfying the orthogonality condition of the structural shocks. The variances, i.e. the diagonal elements, in the first state are normalized to unity, such that $\Lambda(1)=I_{K}$.

The assumption on the constancy of $B$ may be challenged and newer literature is adopting more flexible models with state dependent impact matrices (Bacchiocchi and Fanelli, 2015; Podstawski and Velinov, 2016). However, the feature of interest in the current setup is the ability to make use of the statistical properties of the data in order to identify a set of structural shocks, rather than the analysis of a potential state dependency of the shock transmission that could be introduced into the model via a regime switching structural impact matrix $B$.

Given the assumption on the constancy of the structural impact matrix $B$, the setup allows - assuming that the diagonal elements of $\Lambda$ are distinct (Lanne et al., 2010) - for the uncovering of a set of orthogonal structural shocks from the reduced form VAR model that are consistent with the statistical properties of the data. Given distinct diagonal elements in the covariance matrix of the structural shocks, the structural impact matrix $B$ is unique up to sign and column permutations.

We exploit this feature of the MSH-VAR setup for the identification of the structural shocks of interest. As mentioned above, making use of the statistical properties of the data for identification of a set of structural shocks is particularly helpful in cases where economic theory does not provide a set of restrictions that is suited to identify of the shocks of interest.

Under the assumption that the conditions for identification via heteroscedasticity are met by the models - an assumption that we address in the subsequent section - the MSH-SVAR model leaves us with three orthogonal shocks, $\varepsilon_{1}, \varepsilon_{2}$ and $\varepsilon_{3}$. These shocks need to be labeled and, hence, endowed with economic interpretation. We turn to this issue in Section 7.2. 


\section{Results}

This section presents the results from the MSH-SVAR model for Spain and Italy. Based on information criteria for the linear model, we introduce two lags for the Italian model and three for the Spanish model. In order to keep the model parsimonious and since we mainly use the state switching property of the model for the purpose of identification, we resort to choosing two states for the Markov process. ${ }^{29}$ Before turning to the analysis of the impulse responses and the historical decomposition, we report the state probabilities of the Markov process and a number of results related to the identification of the shocks.

\subsection{State probabilities}

The smoothed state probabilities provide a first assessment of the suitability of the specified MSH-VAR model. Figure 4 reports the state probabilities for the high volatility state for the Spanish and Italian model.

Both models indicate a state switches around 2007/2008, capturing the emergence of the financial crisis. The Markov-switching model identifies a low volatility state roughly before default of Lehman Brothers and a high volatility state afterwards, in which both economies remain for the remainder of the sample. The state probabilities clearly reflect the heteroscedasticity pattern in the data (see Figure D.11 in the Appendix D). All three endogenous variables exhibit low volatility in the period up to 2007 and higher volatility afterwards.

Figure D.12 in the Appendix D plots the reduced form residuals and the standardized reduced form residuals from both MSH-VAR models. The standardization takes into account the two volatility regimes, and allows for an informal assessment of the fit of the model. Formally, the vector of standardized residuals $\hat{u}_{t}^{z}$ is computed by

$$
\hat{u}_{t}^{z}=\hat{\Sigma}_{t \mid t-1}^{-1 / 2} \hat{u}_{t}
$$

where $\hat{u}_{t}$ is the vector of estimated residuals and $\hat{\Sigma}_{t \mid t-1}^{-1 / 2}$ is the estimated variance covariance

\footnotetext{
${ }^{29}$ We attempt to investigate the data's preferences for higher order Markov-switching models by estimating the MSH-SVAR with three and four states. Maximizing the likelihood becomes increasingly more complicated with an increasing number of states. Given the sufficiency of two states to identify the three shocks in the model, we resort to two states for the Markov process.
} 


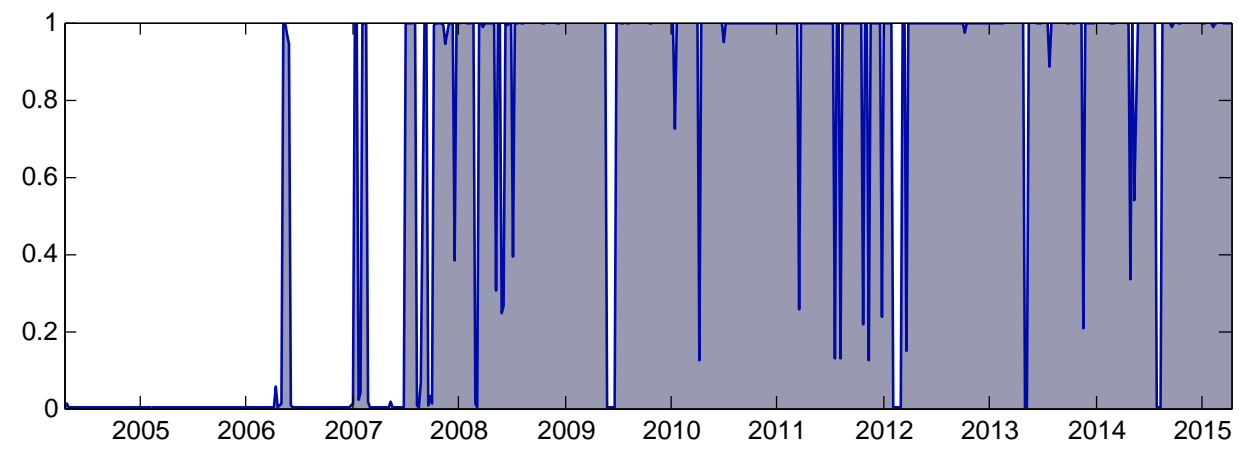

(a) Spain

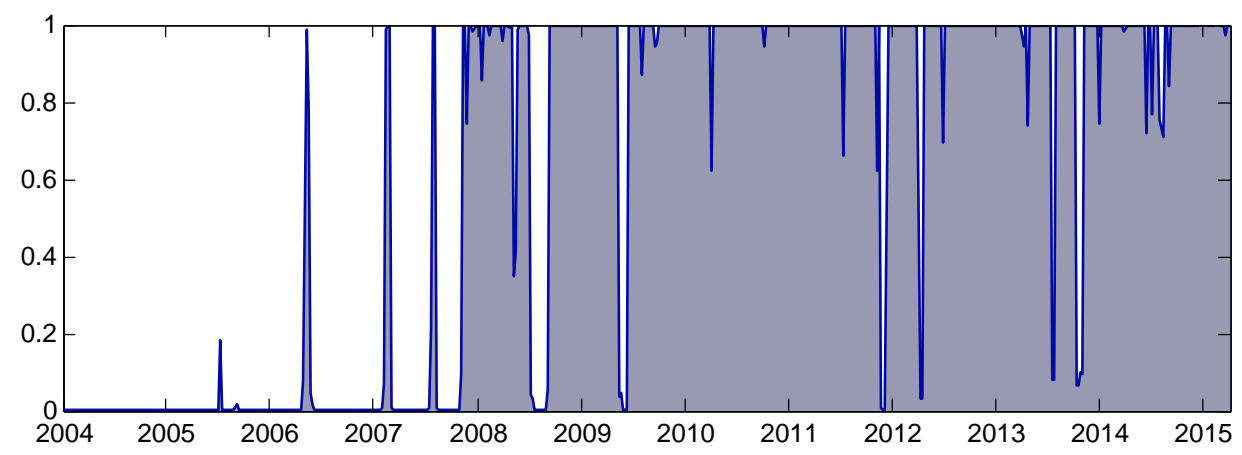

(b) Italy

Figure 4: Smoothed state probabilities for the high volatility state

matrix of the residuals based on the information up to $t-1$, i.e. $\hat{\Sigma}_{t \mid t-1}^{-1 / 2}=\sum_{m=1}^{M} \hat{P}\left(s_{t}=m \mid Y_{t-1}\right) \Sigma_{m}$. The distinct heteroscedasticity pattern present in the non standardized residuals is tempered substantially by the standardization, indicating the models success in capturing the heteroscedasticity in the residuals. Although higher order MSH-VAR models may capture even more of the heteroscedasticity pattern, we conclude that the above state probabilities resemble the recent crisis dynamics, i.e. the heteroscedasticity pattern in the data, in a convincing manner. Next, we discuss issues related to the identification of the model and move from the reduced form to the structural model. 


\subsection{Identification}

In a MSH-VAR model with two states the reduced form variances may be decomposed such that $\Sigma_{u 1}=B B^{\prime}$ and $\Sigma_{u 2}=B \Lambda_{2} B^{\prime}$, where $\Lambda_{2}=\operatorname{diag}\left(\lambda_{21}, \ldots, \lambda_{2 K}\right)$, and all diagonal elements are positive. In order to make use of the statistical properties for the identification of the structural shocks we require the $\lambda_{2 i}$ s representing the variances of the structural shocks to be distinct (Herwartz and Lütkepohl, 2014; Lanne et al., 2010).

Table 2: Relative variances of structural shocks in the high volatility regime

\begin{tabular}{cccc}
\hline & $\lambda_{21}$ & $\lambda_{22}$ & $\lambda_{23}$ \\
\hline \multirow{2}{*}{ ES } & $\begin{array}{c}5246.125 \\
(10.845)\end{array}$ & $\begin{array}{c}23.471 \\
(4.807)\end{array}$ & $\begin{array}{c}5.543 \\
(0.750)\end{array}$ \\
\hline \multirow{2}{*}{ IT } & $\begin{array}{c}1339.912 \\
\text { (14.847) }\end{array}$ & $\begin{array}{c}13.881 \\
(1.969)\end{array}$ & $\begin{array}{c}2.877 \\
(0.533)\end{array}$ \\
\hline
\end{tabular}

Notes: Standard errors in parentheses.

Table 2 reports the estimated relative variances of the structural shocks, $\lambda_{2 i}$, for both models for the second state. Recall that the variances of the structural shocks are normalized to unity for the first state, i.e. $m=1$. Clearly, the second state is the one exhibiting higher volatility and, indicating turbulent or crisis times. The point estimates indicate reasonable distance between the $\lambda_{2 i}$ s taking into account the size of their standard errors. Overall, the point estimates and standard errors of the $\lambda_{2 i}$ s strongly indicate that identification is achieved based on the properties of the data.

\subsection{Labeling the uncorrelated shocks}

So far we have identified a set of three orthogonal structural shocks $-\epsilon_{1}, \epsilon_{2}$ and $\epsilon_{3}$ - that we would like to label as fundamental default risk, risk aversion and uncertainty shocks in order to make them economically interpretable. For the labeling we make use of the fact that proxies for two of the structural shocks we aim to identify are included in the vector of endogenous variables. We label the shock with the maximum contribution to the forecast error variance of the risk aversion proxy to be the risk aversion shock and the one with the maximum 
contribution to the forecast error variance of the uncertainty measure to be the uncertainty shock. The remaining structural shock is labeled fundamental default risk shock. Table D.4 and D.5 report the forecast error variance decomposition (FEVD) for the first state at different horizons and allow a clear labeling based on the rational discussed above. We use the FEVD for the first state as it is the normal or non-crisis state within the setup, however, the labeling would be exactly the same if we took into account the higher relative variances of the second state in the FEVD.

Figure D.13 in the Appendix D plots the three structural shocks and provides an opportunity for a further assessment of the labeling based on the forecast error variance decompositions. The dynamics of the shocks look quite similar among the models: The fundamental default risk shock exhibits highest volatility during the sovereign debt crisis emerging around 2011/12 and has a very distinct pattern of heteroscedasticity. The risk aversion shock exhibits the strongest impulses during the unfolding of the financial crisis in 2008 - a pattern also found by Guiso et al. (2013) based on survey data of customers of Italian banks and in line with the general notion of countercyclical risk aversion (Cohn et al., 2015). In addition, this pattern seems to match the dynamics of alternative proxies for risk aversion such as the Baa-Aaa corporate bond spread provided by Moody's, which similarly jumps during this time period. Finally, the uncertainty shock is less clustered among the time dimension than the other two, but still exhibits phases of higher volatility during both, the financial crisis and the European sovereign debt crisis broadly in line with the literature on economic uncertainty (Bloom, 2014). Overall the dynamics of the structural shocks strongly support the labeling based on the forecast error variance contributions.

In addition to the labeling of the structural shocks the FEVD provides first insights into the role of the three shocks for the sovereign financing premium. Clearly, the fundamental default risk shock dominates the variations in CDS, but risk aversion and uncertainty shocks make up for a substantial share of the variation in CDS in both models, increasing in the forecast horizon. Also note that the risk aversion measure seems to contain a significant uncertainty component, with uncertainty shocks accounting already for 17 and 21 percent of the variation in risk aversion at a five week horizon, further increasing at larger horizons. We take this as first evidence of an impact of uncertainty shocks on investors' risk aversion in line with the 
predictions of Proposition 1. As opposed to that, the uncertainty measure seems rather well described by its own shock — and less affected by the fundamental default risk and the risk aversion shock - judged by the forecast error variance decomposition.

Based on the identification and the labeling of the structural shocks, we turn to the impulse responses analysis and the historical decomposition of the financing premia in the subsequent sections.

\subsection{Impulse responses}

Impulse responses from both models are plotted in Figure 5. Confidence sets are based on a fixed design wild bootstrap in order to re-sample without corrupting the heteroscedasticity properties of the data. ${ }^{30}$ The responses of the CDS spreads are in line with the theoretical prediction of the model presented in Section 3. All three shocks, the fundamental default risk shock, the risk aversion shock, and the uncertainty shock impact positively on the CDS, increasing the borrowing cost for the sovereign. Among the three shocks, the fundamental default risk shock has the largest short run impact on the sovereign financing cost, followed by the uncertainty and the risk aversion shock — in line with the findings from the forecast error variance decomposition in Tables D.4 and D.5 in the Appendix D. At longer horizons, the uncertainty shock impacts sovereign financing costs even stronger than the fundamental default risk shock in the low volatility regime, although the fundamental default risk shock becomes by far the strongest driver of sovereign CDS in the high volatility regime plotted in Figure D.14 in the Appendix D. Note that qualitatively the impulse responses in the first regime and the second regime are identical by construction. The only difference stems from the higher variances of the structural shocks that scales up the set of impulses.

Quantitatively a one standard deviation uncertainty shock increases CDS by 0.5 to 1 basis points in the first regime of the MSH-SVAR model and between 1 and 1.5 basis points in the second regime. The effect of a uncertainty shock on CDS is somewhat comparable to that of a risk aversion shock, both with a somewhat larger impact in the high volatility regime.

\footnotetext{
${ }^{30}$ For further details on the bootstrapping procedure see Podstawski and Velinov (2016). Brüggemann et al. (2016) argue that block bootstrapping would be superior to wild bootstrapping approaches, because the latter fail to correctly replicate the fourth moments structure of the residuals. Against the backdrop of minor distortions for the point wise confidence bands, we follow the literature and deploy a wild bootstrapping to obtain confidence bands.
} 

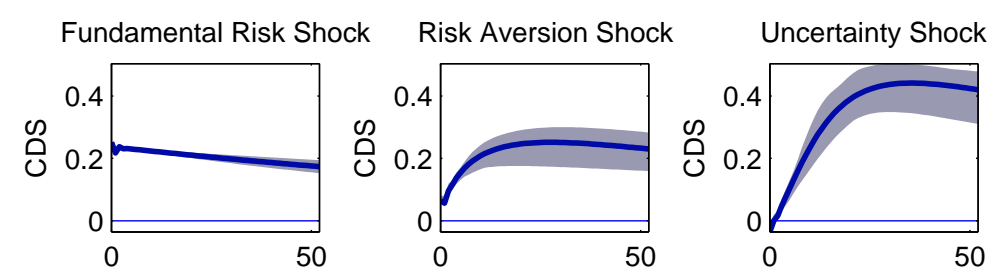

Fundamental Risk Shock
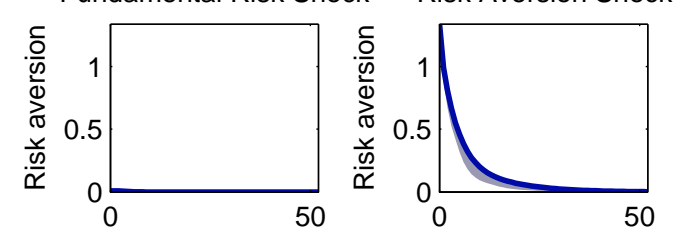

Uncertainty Shock

Fundamental Risk Shock Risk Aversion Shock
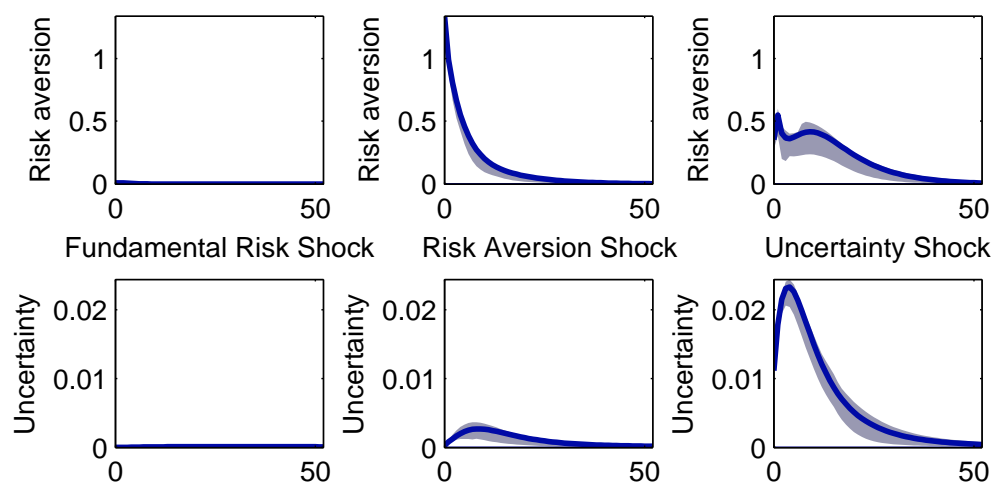

(a) Spain
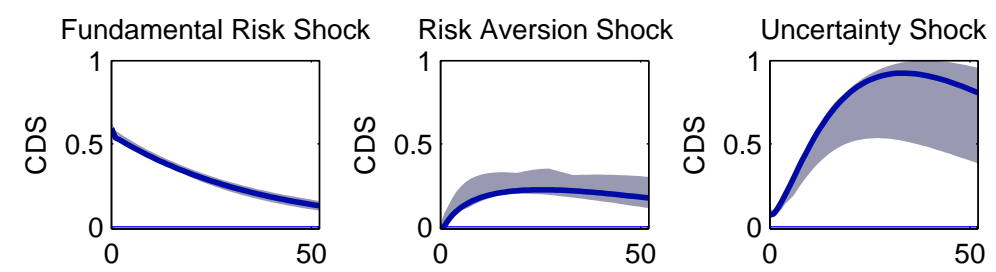

Fundamental Risk Shock Risk Aversion Shock
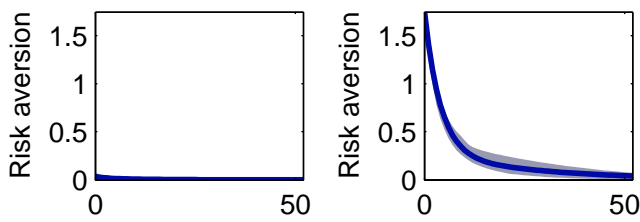

Uncertainty Shock

Fundamental Risk Shock Risk Aversion Shock
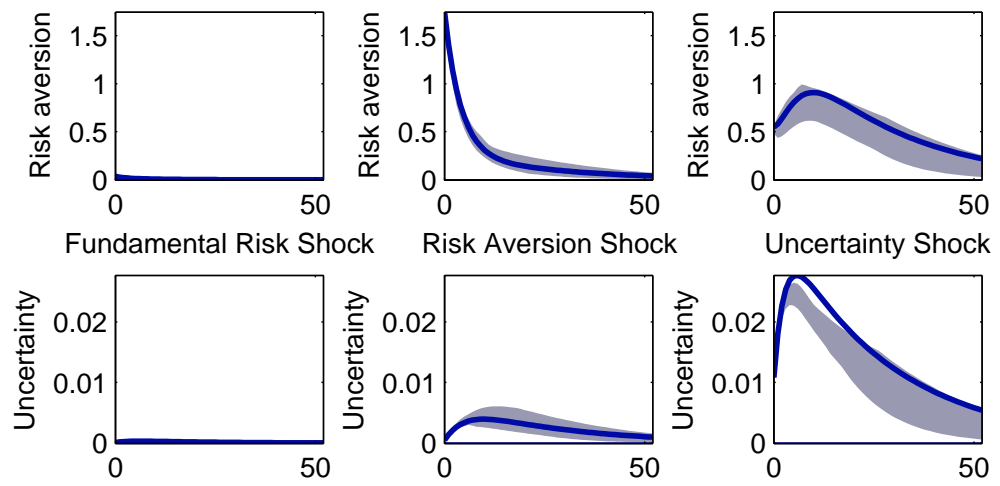

(b) Italy

Figure 5: Impulse responses with $68 \%$ confidence intervals based on 1000 bootstrap replications, low volatility state

A fundamental default risk shock of one standard deviation, however, has an impact effect of about 20 basis points in the high volatility regime, clearly dominating the risk aversion 
and uncertainty shocks. Overall the impulse responses for both economies are qualitatively and quantitatively very similar. They only feature slight differences in the persistence of the responses of the CDS to the three shocks.

The impulse response also allow for empirically assessing the prediction of Proposition 1; that is - given ambiguity averse investors with preferences further featuring varying relative risk aversion in wealth, and thus ambiguity - a positive response of investors' risk aversion to uncertainty shocks. Indeed, in both models we find a strong positive response of the measure of risk aversion to uncertainty shocks. This is in line with the large fraction of the forecast error variance of the risk aversion measure driven by uncertainty shocks. We take this as strong evidence in support of Proposition 1.

\subsection{Historical decomposition}

In order to assess the contributions of the three shocks to sovereign CDS, we conduct a historical decomposition based on the structural shocks. The series of structural shocks is constructed based upon equation (19) using the structural impact matrix $B$ and the observable reduced form residuals. The Wald decomposition of the model described by equation (18) allows for expressing the endogenous variables at time $t$ as a linear combination of initial values and structural shocks in the past according to

$$
\begin{aligned}
y_{t}-\hat{\mu} & =\sum_{i=0}^{t-1} \hat{\phi}_{i} \hat{u}_{t-i}+\hat{A}_{0} y_{0}+\ldots+\hat{A}_{p} y_{-p+1} \\
& =\sum_{i=0}^{t-1} \hat{\phi}_{i} \hat{B} \hat{\varepsilon}_{t-i}+\hat{A}_{0} y_{0}+\ldots+\hat{A}_{p} y_{-p+1}
\end{aligned}
$$

where $\hat{\phi}_{i}$ is the matrix of impulse response coefficients $\hat{\phi}_{i}=\sum_{j=1}^{i} \hat{\phi}_{i-j} \hat{A}_{j}$ with $i=1,2, \ldots$, $\hat{\phi}_{0}=I_{K}$ and $\hat{A}_{j}=0$ for $j>p$ (see Lütkepohl, 2005, Chapter 2) and we ignore the deterministic and exogenous terms in equation (18) that are not relevant for the impulse responses. The historical decomposition of the sovereign CDS variable into the three structural shocks is reported in Figure 6. It clearly supports the hypothesis of risk aversion and uncertainty shocks being relevant drivers of sovereign financing premia, notwithstanding the fact that fundamental 
default risk shocks account for by far the largest share in CDS spreads, especially in later stages of the sovereign debt crisis.

The decomposition indicates large positive contributions of both increased risk aversion and uncertainty to the financing premium of the Spanish and the Italian sovereign. Shocks to economic uncertainty make up for up to about 25 basis points in Spanish CDS spreads and 15 basis points in Italian CDS spreads, playing quantitatively a similar role to changes in investors risk aversion. The Spanish sovereign faced an increase in CDS of up to 25 basis points driven by an increase in risk aversion. Similarly, the Italian financing premium increased by up to 15 basis points due to rising risk aversion among international investors.

Our findings are in line with the literature that documents a crucial role of time variations in risk aversion for the pricing of sovereign debt. ${ }^{31}$ Barrios et al. (2009) argue that general risk perception and its interaction with macroeconomic fundamentals are strong driving forces of yield spreads in the euro area. Sgherri and Zoli (2009) provide evidence that 15 to 30 basis points of the increase in Spanish and Italian yield spreads from late 2008 to early 2009 are attributable to increased risk aversion. Similarly, Caceres et al. (2010) find a positive contribution from global risk aversion to changes in Spanish yield spreads during 2009 but not for changes in Italian yield spreads.

While the sharp increase in financing premia for the sovereigns was fueled by risk aversion and uncertainty at the onset of the sovereign debt crisis, the picture is different for later stages of the crisis. Compared to the large contribution by fundamental default risk shocks, there is only a minor impact from risk aversion and uncertainty shocks on sovereign financing premia, especially in 2012 when market participants became increasingly concerned about redenomination risk. This form of risk refers to the exit of member countries from the monetary union and the redenomination of their public and private liabilities. As we do not explicitly account for this specific form of exchange rate risk, it is part of the fundamental default risk shock identified in our setup. In line with the large share of fundamental default risk driving CDS upward during 2012, De Santis (2015) finds that close to half of the sovereign yield spreads

\footnotetext{
${ }^{31}$ Note that we do not decompose CDS into a default-risk component and a risk premium, as do, for example, Longstaff et al. (2011), who find about one third of the CDS spread to be associated with the risk premium. Instead we assess the effects of changes in the risk aversion over time, against the backdrop of a steady-state risk aversion in the VAR model considered.
} 
Fundamental Risk Shock
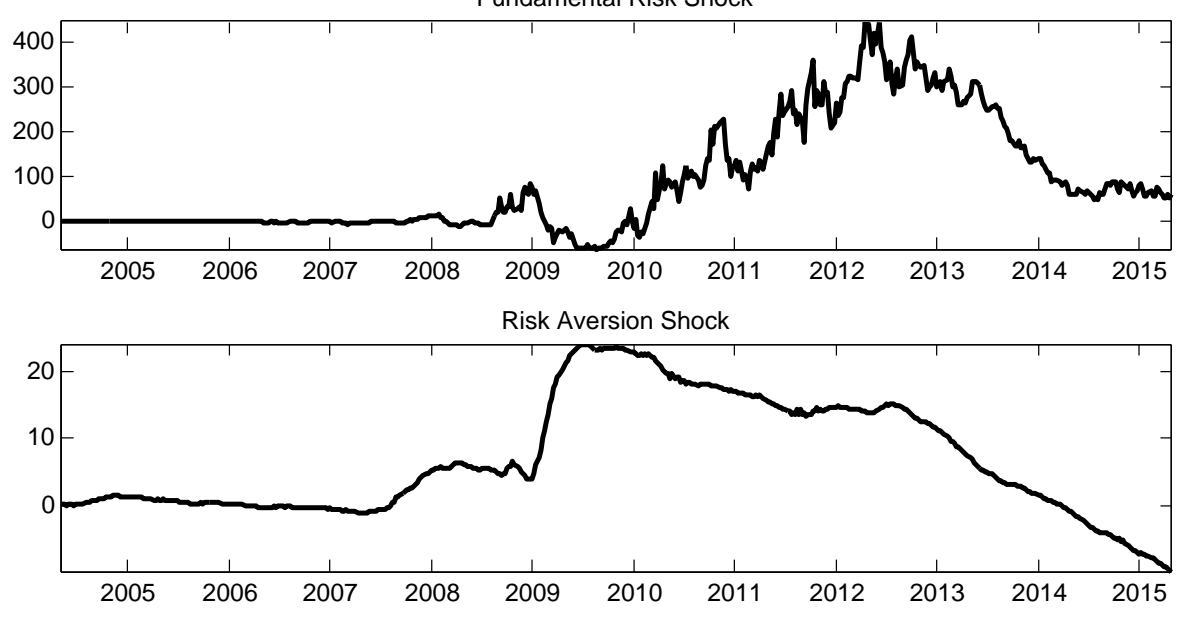

Uncertainty Shock

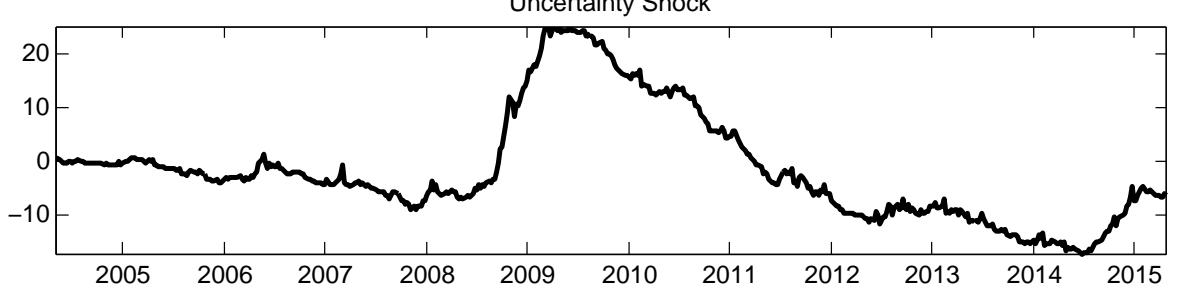

(a) Spain
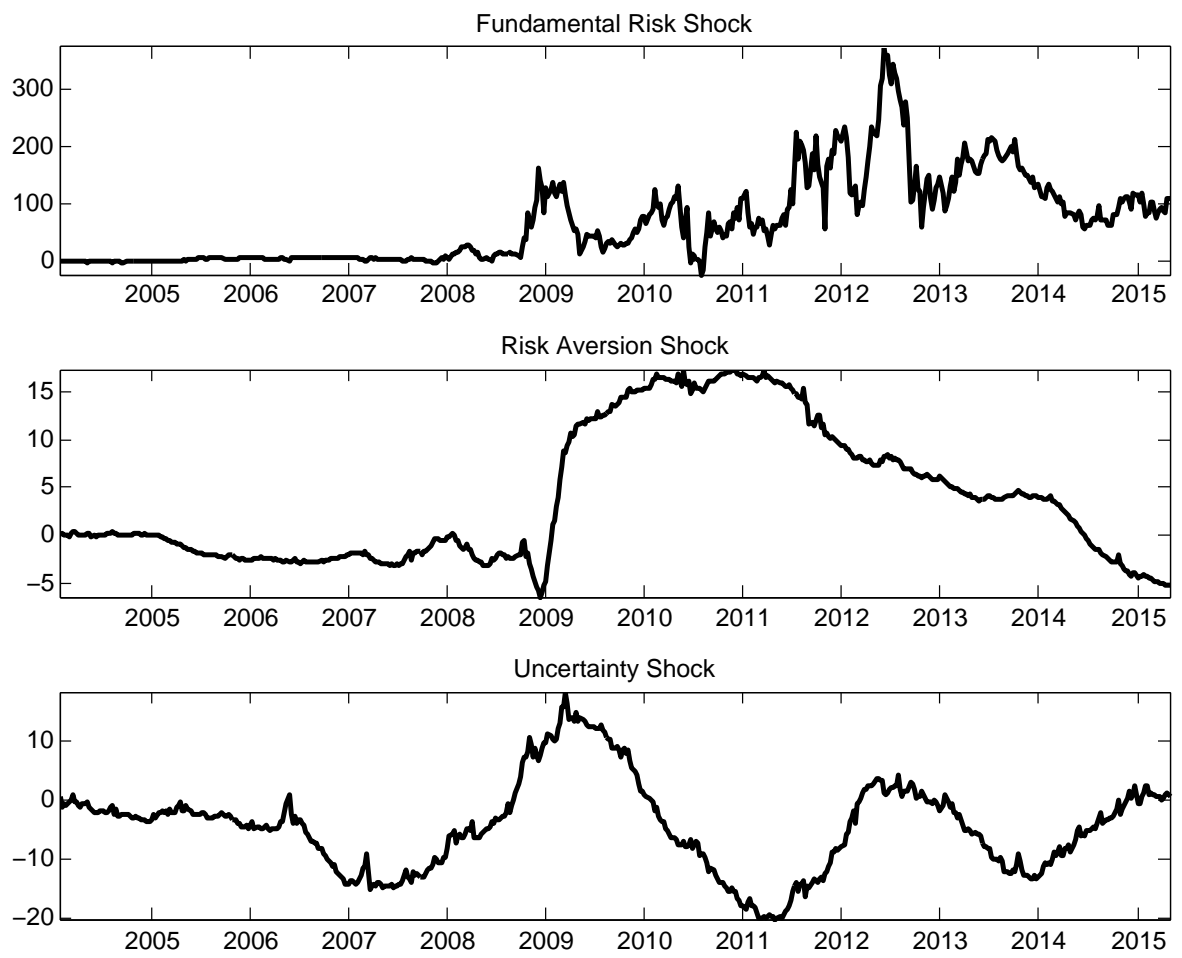

(b) Italy

Figure 6: Historical decomposition of sovereign CDS of Italy and Spain 
were accounted for by redenomination risk in the first quarter of 2012.

Overall, we find clear evidence in support of a channel running from macroeconomic uncertainty to sovereign financing premia discussed in Section 3: Exogenous variations in uncertainty increase sovereign yields and make up for a non-negligible share in sovereign CDS. At the onset of the sovereign debt crisis in the euro area uncertainty shocks accounted for up to 15 basis points in Italian and up to 25 basis points in Spanish CDS spreads, an effect that is quantitatively comparable to the premium originating in rising risk aversion among international investors in the context of the global financial crisis.

\section{Conclusion}

In this paper we theoretically and empirically investigate the effects and interplay of timevarying risk aversion and ambiguity in asset pricing using the case of sovereign debt markets.

Using a two-period consumption-based asset pricing model with optimal sovereign default, we distinguish between the effects of changes in risk aversion and ambiguity for the pricing of government debt. In order to arrive at an analytical decomposition of the price for public debt, we assume that the investors are (i) risk averse, (ii) ambiguity averse, and (iii) have habit persistence in consumption. We show that risk aversion and ambiguity aversion lower bond prices and, hence, increase sovereign yields. Further, the model features an endogenous relationship between ambiguity and risk aversion: An increase in ambiguity affects the worst case prior of ambiguity averse agents, which feeds into higher levels of relative risk aversion.

In a second part, we take this theoretical decomposition of prices for government debt to the data. Since ambiguity is unobservable, we use a measure of macroeconomic uncertainty as a proxy in the empirical analysis. In order to overcome the observational equivalence between the effects of time-varying risk aversion and changes in ambiguity, we set up a structural VAR model and exploit the statistical properties of the data. We find, firstly, that shocks to macroeconomic uncertainty significantly increase international investors' risk aversion and account for a substantial share in the variance of the risk aversion measure, in line with the predictions of the theoretical model. Secondly, uncertainty shocks make up for a non-negligible share in Spanish and Italian sovereign yield spreads of up to 25 basis points at the onset of the 
sovereign debt crisis. Thereby we show that uncertainty has quantitatively comparable effects as time-varying risk aversion during this period.

The results underline the relevance of macroeconomic ambiguity for the determination of asset prices and as a potential amplifier during times of economic crises. Specifically, we see ambiguity as a complementary source for time-varying risk aversion, along with changes in the level of wealth or habit persistence in consumption. Thereby, macroeconomic ambiguity is found to be a root cause for risk attitudes more generally. The theoretical and empirical connection between macroeconomic ambiguity and risk aversion documented in this paper opens up interesting avenues for future theoretical and empirical research. 


\section{References}

Abel, A. B. (1990). Asset prices under habit formation and catching up with the joneses. American Economic Review: Papers 85 Proceedings 80(2), 38-42.

Abel, A. B. (1999). Risk premia and term premia in general equilibrium. Journal of Monetary Economics 43, 3-33.

Aizenman, J., M. Hutchison, and Y. Jinjarak (2013). What is the risk of european sovereign debt defaults? fiscal space, cds spreads and market pricing of risk. Journal of International Money and Finance 34, 37-59.

Alary, D., C. Gollier, and N. Treich (2013). The effect of ambiguity aversion on insurance and self-protection. The Economic Journal 123(573), 1188-1202.

Amato, J. D. (2005). Risk aversion and risk premia in the cds market. BIS Quarterly Review, December.

Arellano, C. (2008). Default risk and income fluctuations in emerging economies. American Economic Review 98(3), 690-712.

Arghyrou, M. G. and A. Kontonikas (2012). The emu sovereign-debt crisis: Fundamentals, expectations and contagion. Journal of International Financial Markets, Institutions and Money 22(4), 658-677.

Arrow, J. K. (1963). Liquidity preference. Lecture IV in Lecture Notes for Economics 285, The Economics of Uncertainty (undated, Stanford University), 33-53.

Bacchiocchi, E. and L. Fanelli (2015). Identification in structural vector autoregressive models with structural changes, with an application to us monetary policy. Oxford Bulletin of Economics and Statistics 7r(6), 761-779.

Baker, S. R., N. Bloom, and S. J. Davis (2013). Measuring economic policy uncertainty. Unpublished Manuscript, Stanford University. 
Barrios, S., P. Iversen, M. Lewandowska, and R. Setzer (2009). Determinants of intra-euro area government bond spreads during the financial crisis. European Economy Economic Papers (288).

Bekaert, G. and M. Hoerova (2014). The vix, the variance premium and stock market volatility. Journal of Econometrics 183(2), 181-192.

Bekaert, G., M. Hoerova, and M. Lo Duca (2013). Risk, uncertainty and monetary policy. Journal of Monetary Economics 60(7), 771-788.

Bernoth, K. and B. Erdogan (2012). Sovereign bond yield spreads: A time-varying coeficient approach. Journal of International Money and Finance 31(3), 639-659.

Bloom, N. (2014). Fluctuations in uncertainty. Journal of Economic Perspectives 28(2), 153175.

Bollerslev, T., M. Gibson, and H. Zhou (2011). Dynamic estimation of volatility risk premia and investor risk aversion from option-implied and realized volatilities. Journal of Econometrics 160(1), 235-245.

Bollerslev, T., G. Tauchen, and H. Zhou (2009). Expected stock returns and variance risk premia. Review of Financial Studies 22(11), 4463-4492.

Borgy, V., T. Laubach, J.-S. Mésonnier, and J.-P. Renne (2011). Fiscal sustainability, default risk and euro area sovereign bond spreads. Banque de France Working Paper (350).

Borri, N. and A. Verdelhan (2011). Sovereign risk premia. SSRN Working Paper (1343746).

Brüggemann, R., C. Jentsch, and C. Trenkler (2016). Inference in VARs with conditional heteroskedasticity of unknown form. Journal of Econometrics 191(1), 69-85.

Brunnermeier, M. K. and S. Nagel (2008). Do wealth fluctuations generate time-varying risk aversion?: Micro-evidence on individual's asset allocation. American Economic Review 98(3), $713-736$.

Caceres, C., V. Guzzo, and M. Segoviano Basurto (2010). Sovereign spreads: Global risk aversion, contagion or fundamentals? IMF working papers, 1-29. 
Campbell, J. Y. and J. H. Cochrane (1999). By force of habit: A consumption-based explanation of aggregate stock market behavior. Journal of Political Economy 107(2), 205.

Cherbonnier, F. and C. Gollier (2015). Decreasing aversion under ambiguity. Journal of Economic Theory 157, 606-623.

Chetty, R. and A. Szeidl (2005). Consumption commitments: Neoclassical foundations for habit formation. Unpublished Manuscript, University of California, Berkeley.

Cohn, A., J. Engelmann, E. Fehr, and M. A. Maréchal (2015). Evidence for countercyclical risk aversion: an experiment with financial professionals. The American Economic Review 105(2), 860-885.

Constantinides, G. (1990). Habit formation: A resolution of the equity premium puzzle. Journal of Political Economy 98(3), 519-543.

D'Agostino, A. and M. Ehrmann (2014). The pricing of g7 sovereign bond spreads: The times, they are a-changin. Journal of Banking \& Finance 47, 155-176.

De Santis, R. A. (2015). A measure of redenomination risk. ECB Working Paper Series (1785).

Dow, J. and S. R. d. C. Werlang (1992). Uncertainty aversion, risk aversion, and the optimal choice of portfolio. Econometrica 60(1), 197-204.

Engler, P. and C. Große Steffen (2016). Sovereign risk, interbank freezes, and aggregate fluctuations. European Economic Review 87, 34-61.

Epstein, L. G. and M. Schneider (2010). Ambiguity and asset markets. Annual Review of Financial Economics 2(1), 315-346.

Epstein, L. G. and T. Wang (1994). Intertemporal asset pricing under knightian uncertainty. Econometrica 62(2), 283-322.

Fontana, A. and M. Scheicher (2010). An analysis of euro area sovereign cds and their relation with government bonds. ECB working paper (1271). 
Ghirardato, P., F. Maccheroni, and M. Marinacci (2004). Differentiating ambiguity and ambiguity attitude. Journal of Economic Theory 118(2), 133-173.

Gilboa, I. and D. Schmeidler (1989). Maxmin expected utility with non-unique prior. Journal of Mathematical Economics 18, 141-153.

Grauwe, P. d. and Y. Ji (2012). Mispricing of sovereign risk and macroeconomic stability in the eurozone. Journal of Common Market Studies 50(6), 866-880.

Große Steffen, C. (2015). Uncertainty shocks and non-fundamental debt crises: an ambiguity approach. SSRN eLibrary (2602716).

Guiso, L., P. Sapienza, and L. Zingales (2013). Time varying risk aversion. NBER Working Papers (19284).

Haan, L. d., J. Hessel, and van den End, Jan Willem (2014). Are european sovereign bonds fairly priced? the role of modelling uncertainty. Journal of International Money and Finance 47 , 239-267.

Hagen, J. v., L. Schuknecht, and G. Wolswijk (2011). Government bond risk premiums in the eu revisited: The impact of the financial crisis. European Journal of Political Economy 27(1), $36-43$.

Hansen, L. P., T. J. Sargent, and T. D. Tallarini (1999). Robust permanent income and pricing. Review of Economic Studies 66(4), 873-907.

Herwartz, H. and H. Lütkepohl (2014). Structural vector autoregressions with Markov switching: Combining conventional with statistical identification of shocks. Journal of Econometrics $183(1), 104-116$.

Hilscher, J. and Y. Nosbusch (2010). Determinants of sovereign risk: Macroeconomic fundamentals and the pricing of sovereign debt. Review of Finance 14(2), 235-262.

Ilut, C. L. and M. Schneider (2014). Ambiguous business cycles. American Economic Review 104 (8), 2368-2399. 
Jurado, K., S. C. Ludvigson, and S. Ng (2015). Measuring uncertainty. American Economic Review $105(3), 1177-1216$.

Klibanoff, P., M. Marinacci, and S. Mukerji (2005). A smooth model of decision making under ambiguity. Econometrica 73(6), 1849-1892.

Knight, F. H. (1921). Risk, uncertainty, and profit. Boston and MA: Hart Schaffner \& Marx and Houghton Mifflin Co.

Lanne, M. and H. Lütkepohl (2008). Identifying monetary policy shocks via changes in volatility. Journal of Money, Credit and Banking 40(6), 1131-1149.

Lanne, M., H. Lütkepohl, and K. Maciejowska (2010). Structural vector autoregressions with markov switching. Journal of Economic Dynamics and Control 34(2), 121-131.

Laubach, T. (2009). New evidence on the interest rate effects of budget deficits and debt. Journal of the European Economic Association 7(4), 858-885.

Lizarazo, S. V. (2013). Default risk and risk averse international investors. Journal of International Economics 89, 317-330.

Longstaff, F. A., J. Pan, L. H. Pedersen, and K. J. Singleton (2011). How sovereign is sovereign credit risk? American Economic Journal: Macroeconomics 3(2), 75-103.

Ludvigson, S. C. and S. Ng (2007). The empirical risk-return relation: a factor analysis approach. Journal of Financial Economics 83(1), 171-222.

Lütkepohl, H. (2005). New introduction to multiple time series analysis. Springer Verlag (Berlin).

Lütkepohl, H. and A. Netšunajev (2014). Disentangling demand and supply shocks in the crude oil market: How to check sign restrictions in structural vars. Journal of Applied Econometrics 29(3), 479-496.

Maenhout, P. J. (2004). Robust portfolio rules and asset pricing. Review of Financial Studies 17(4), 951-983. 
Podstawski, M. and A. Velinov (2016). The state dependent impact of bank exposure on sovereign risk. Unpublished Manuscript.

Pratt, W. J. (1964). Risk aversion in the small and in the large. Econometrica 32(1/2), $122-136$.

Rigobon, R. (2003). Identification through heteroskedasticity. Review of Economics and Statistics 85(4), 777-792.

Samuelson, P. A. (1969). Lifetime portfolio selection by dynamic stochastic programming. Review of Economics and Statistics 51(3), 239-246.

Schumacher, C. and J. Breitung (2008). Real-time forecasting of german gdp based on a large factor model with monthly and quarterly data. International Journal of Forecasting $24(3)$, $386-398$.

Sgherri, S. and E. Zoli (2009). Euro area sovereign risk during the crisis. IMF Working Papers (222).

Trojani, F. and P. Vanini (2004). Robustness and ambiguity aversion in general equilibrium. Review of Finance 8(2), 279-324. 


\section{A Numerical model: Solution and calibration}

The model is solved by finding optimal default decisions through backward induction. The borrowing limit of a government in the initial period $\bar{B}_{1}$ is given by the condition that the utility under repayment at $t=1$ in the high productivity state is at least as high as the utility under default, which is given by the value for $\bar{B}_{1}$ that solves the condition ${ }^{32} u\left(F\left(z^{h}, l\right)+\bar{B}_{1}\right)=$ $u\left(g F\left(z^{h}, l\right)\right)$.

For the initial period, default is the optimal choice if expected lifetime-utility under default is strictly larger than expected lifetime-utility under repayment, formally $V^{d}>V^{n d}$, where the two value functions are given by

$$
\begin{aligned}
V^{n d}\left(z_{0}, B_{0}, a, W_{0}\right) & =v\left(y_{0}-q_{0} B_{1}+B_{0}\right)+\beta E_{t}\left[V_{1}\left(z_{1}, B_{1}\right)\right] \\
V^{d}\left(z_{0}\right) & =v\left(g y_{0}\right)+\beta E_{t}\left[V_{1}\left(z_{1}, 0\right)\right]
\end{aligned}
$$

and where the continuation value can be derived by using probabilities for aggregate productivity to write out expectations as

$$
E_{t}\left[V_{1}\left(z_{1}, B_{1}\right)\right]=\left(1-\frac{\bar{x}-\tilde{x}_{l b}}{\tilde{x}_{u b}-\tilde{x}_{l b}}\right) u\left(F\left(z^{h}, l\right)+B_{1}\right)+\left(\frac{\bar{x}-\tilde{x}_{l b}}{\tilde{x}_{u b}-\tilde{x}_{l b}}\right) u\left(F\left(z^{l}, l\right)\right) .
$$

Calibration. Let household utility be given by a quadratic utility function:

$$
v\left(c_{0}, c_{1}\right)=\sum_{t=0}^{1} \beta^{t}\left(c_{t}-\frac{\psi}{2}\left(c_{t}\right)^{2}\right)
$$

All remaining parameters are summarized in Table A.3.

Table A.3: Calibration

\begin{tabular}{lcc}
\hline & parameter & value \\
\hline Domestic economy & & \\
Initial stock of debt & $B_{0}$ & 0.03 \\
Quadratic preference parameter & $\psi$ & 0.4 \\
Default penalty & $g$ & 0.86 \\
Low productivity level & $z_{l}$ & -0.1 \\
High productivity level & $z_{h}$ & 0.1 \\
International investors & & \\
Risk aversion & $\gamma$ & 2 \\
Habit parameter & $h$ & 0.1 \\
Investors' discount factor & $\beta$ & 0.99 \\
Initial amount riskfree assets & $S_{0}$ & 1.6 \\
Productivity threshold & $\bar{x}$ & 0.05 \\
A priori lower bound & $\tilde{x}_{l b}$ & 0 \\
A priori upper bound & $\tilde{x}_{l b}$ & 1 \\
\hline
\end{tabular}

\footnotetext{
${ }^{32}$ See that default is optimal in the low productivity state for any $B_{1}<0$, since $u\left(F\left(z^{l}, l\right)+\bar{B}_{1}\right)<u\left(F\left(z^{l}, l\right)\right)$.
} 


\section{B Construction of the uncertainty measure}

The following summary is based upon Jurado et al. (2015, section 3.1), which the reader is referred to for further details. Recall that uncertainty of variable $y_{j}$ at time $t$ for horizon $h$ of a single series defined by

$$
\mathcal{U}_{j, t}^{y}(h) \equiv \sqrt{E\left\{\left[y_{j t+h}-E\left(y_{j, t+h} \mid I_{t}\right)\right]^{2} \mid I_{t}\right\}} .
$$

Assume that $X_{i t}$ contains the set of predictors used for forecasting and is representable by the following factor structure

$$
X_{i t}=\Lambda_{i}^{F^{\prime}} F_{t}+e_{i t}^{X}
$$

where $F_{t}$ contains the latent factors, $\Lambda_{t}$ the loadings and $e_{i t}^{X}$ the idiosyncratic errors. Forecasts for the series $y_{t}$ are conducted using the following factor augmented autoregressive model

$$
y_{j t+1}=\phi_{j}^{y}(L) y_{j t}+\gamma_{j}^{F}(L) \hat{F}_{t}+v_{j t+1}^{y}
$$

where $\phi_{j}^{y}(L)$ and $\gamma_{j}^{F}(L)$ are polynomials in the lag operator $L, \hat{F}_{t}$ are estimates of $F_{t}$. The one-step-ahead prediction errors for each variable $y_{j}$ and each factor $F_{t}$ are allowed to feature time varying volatility, i.e. $v_{j t+1}^{y}=\sigma_{j t+1}^{y} \epsilon_{j t+1}^{y}$ and $v_{k t+1}^{F}=\sigma_{k t+1}^{F} \epsilon_{k t+1}^{F}$, an assumption that is crucial for the time variation in uncertainty. The forecasts $E\left[y_{j t+h} \mid I_{t}\right]$ are obtained from the factor augmented autoregressive (FAVAR) model, written in companion form as

$$
\left(\begin{array}{c}
\mathcal{F}_{t} \\
Y_{j t}
\end{array}\right)=\left(\begin{array}{cc}
\Phi^{F} & 0 \\
\Lambda_{j}^{\prime} & \Phi_{j}^{Y}
\end{array}\right)\left(\begin{array}{c}
\mathcal{F}_{t-1} \\
Y_{j t-1}
\end{array}\right)+\left(\begin{array}{c}
\mathcal{V}_{t}^{F} \\
\mathcal{V}_{j t}^{Y}
\end{array}\right),
$$

or written more compactly as

$$
\mathcal{Y}_{j t}=\Phi_{j}^{\mathcal{Y}} \mathcal{Y}_{j t-1}+\mathcal{V}_{j t}^{\mathcal{Y}}
$$

where $\mathcal{F}_{t}$ collects the factors and additional predictors used for forecasting, $Y_{j t}$ represents the set of variables that are to be forecasted, $\Lambda_{j}^{\prime}$ and $\Phi_{j}^{y}$ are collections of the coefficients in the matrix polynomial lag operators from the single factor augmented forecasting model. The optimal forecast is given by the conditional mean

$$
E_{t} \mathcal{Y}_{j t+h}=\left(\Phi_{j}^{\mathcal{Y}}\right)^{h} \mathcal{Y}_{j t}
$$

and the forecast error variance at horizon $h=1$ is given by

$$
\Omega_{j t}^{\mathcal{Y}}=E_{t}\left(\mathcal{V}_{j t+1}^{\mathcal{Y}} \mathcal{V}_{j t+1}^{\mathcal{Y} \prime}\right)
$$

In order to obtain the expected forecast uncertainty of a single variable $y_{j t+h}$ based on the information set at time $t$, we select a single entry of the forecast error variance matrix $\Omega_{j t}^{\mathcal{Y}}$ using $\mathbb{1}_{j}$ as a selection vector with unity as its $j$ th element and zeros elsewhere

$$
\mathcal{U}_{j, t}^{y}(1)=\sqrt{\mathbb{1}_{j}^{\prime} \Omega_{j t}^{\mathcal{Y}} \mathbb{1}_{j}} .
$$


Finally, aggregate uncertainty is computed as the average of the individual forecast uncertainties

$$
\mathcal{U}_{t}^{y}(1)=\frac{1}{N} \sum_{j=1}^{N_{y}} \mathcal{U}_{j, t}^{y}(1) .
$$




\section{Risk and uncertainty attitudes}

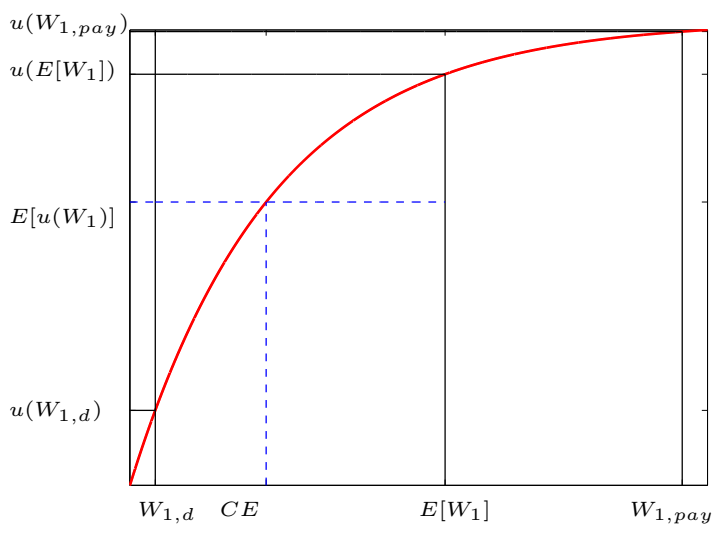

(a) Risk aversion

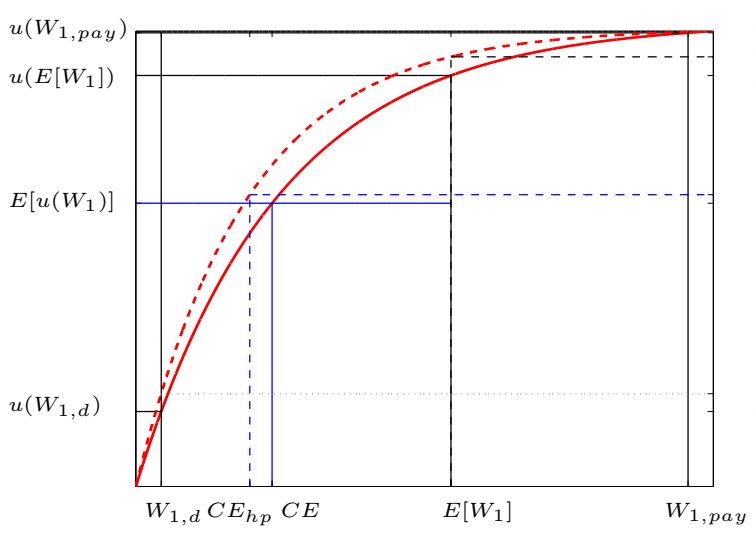

(c) Habit persistence

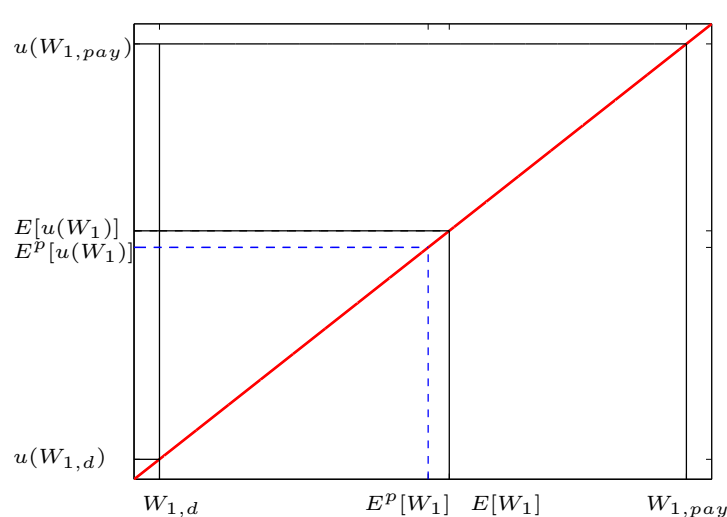

(b) Ambiguity aversion and risk neutrality

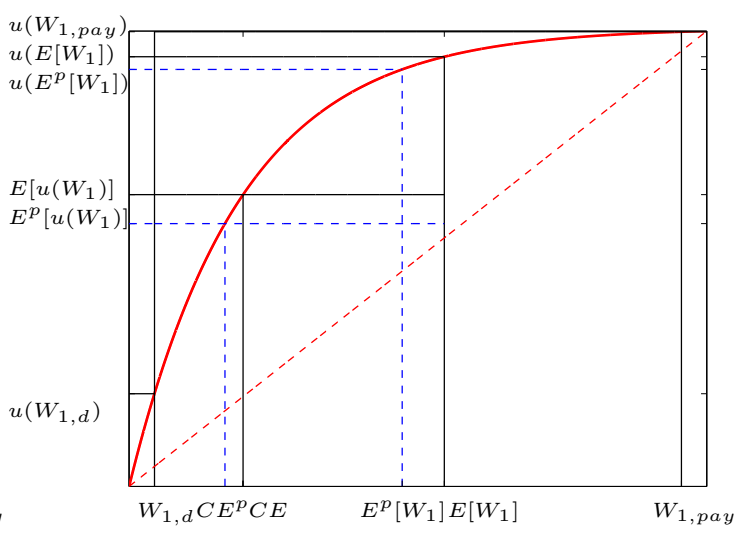

(d) Risk, ambiguity, and habit persistence

Figure C.7: Risk attitudes, utility on y-axis and wealth on x-axis wherever not noted otherwise. 


\section{Tables and figures}

Figure D.8: Timing of events in default model

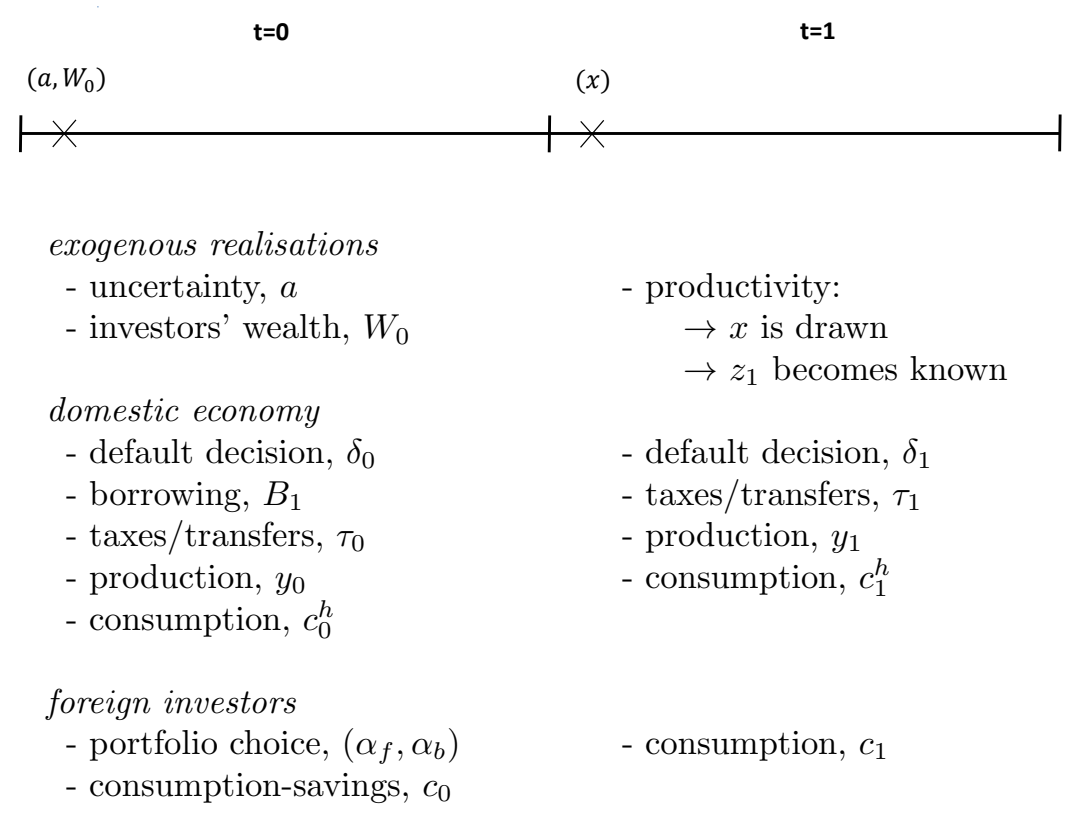

Figure D.9: Simultaneously risky and uncertain bet on sovereign bonds

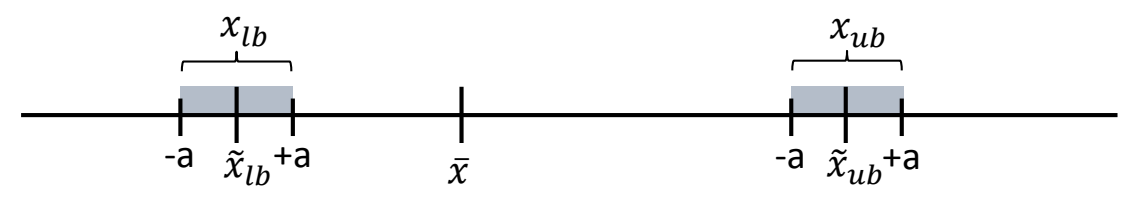


Table D.4: Forecast error variance decomposition from the MSH-SVAR for Spain (low volatility state)

\begin{tabular}{ccccc}
\hline Variable & Horizon & $\varepsilon_{1}$ & $\varepsilon_{2}$ & $\varepsilon_{3}$ \\
\hline \multirow{4}{*}{ CDS } & 1 & $\mathbf{0 . 9 2}$ & 0.06 & 0.02 \\
& 5 & $\mathbf{0 . 8 2}$ & 0.15 & 0.03 \\
& 10 & $\mathbf{0 . 6 0}$ & 0.24 & 0.16 \\
Risk Aversion & 20 & $\mathbf{0 . 3 5}$ & 0.25 & 0.40 \\
\hline \multirow{4}{*}{ Uncertainty } & 1 & 0.00 & $\mathbf{0 . 9 4}$ & 0.06 \\
& 10 & 0.00 & $\mathbf{0 . 8 3}$ & 0.17 \\
& 20 & 0.00 & $\mathbf{0 . 7 4}$ & 0.26 \\
& 1 & 0.00 & $\mathbf{0 . 6 3}$ & 0.37 \\
\hline & 5 & 0.00 & 0.00 & $\mathbf{1 . 0 0}$ \\
& 10 & 0.00 & 0.01 & $\mathbf{1 . 0 0}$ \\
& 20 & 0.00 & 0.02 & $\mathbf{0 . 9 8}$ \\
\hline
\end{tabular}

Table D.5: Forecast error variance decomposition from the MSH-SVAR for Italy (low volatility state)

\begin{tabular}{ccccc}
\hline Variable & Horizon & $\varepsilon_{1}$ & $\varepsilon_{2}$ & $\varepsilon_{3}$ \\
\hline \multirow{4}{*}{ CDS } & 1 & $\mathbf{0 . 9 9}$ & 0.00 & 0.01 \\
& 5 & $\mathbf{0 . 9 3}$ & 0.01 & 0.06 \\
& 10 & $\mathbf{0 . 7 5}$ & 0.04 & 0.22 \\
Risk Aversion & 20 & $\mathbf{0 . 4 1}$ & 0.06 & 0.54 \\
\hline \multirow{4}{*}{ Uncertainty } & 1 & 0.00 & $\mathbf{0 . 9 1}$ & 0.09 \\
& 10 & 0.00 & $\mathbf{0 . 7 9}$ & 0.21 \\
& 20 & 0.00 & $\mathbf{0 . 6 1}$ & 0.39 \\
& 1 & 0.00 & $\mathbf{0 . 4 2}$ & 0.58 \\
\hline & 5 & 0.00 & 0.00 & $\mathbf{1 . 0 0}$ \\
& 10 & 0.00 & 0.02 & $\mathbf{0 . 9 9}$ \\
& 20 & 0.00 & 0.02 & $\mathbf{0 . 9 8}$ \\
\hline
\end{tabular}




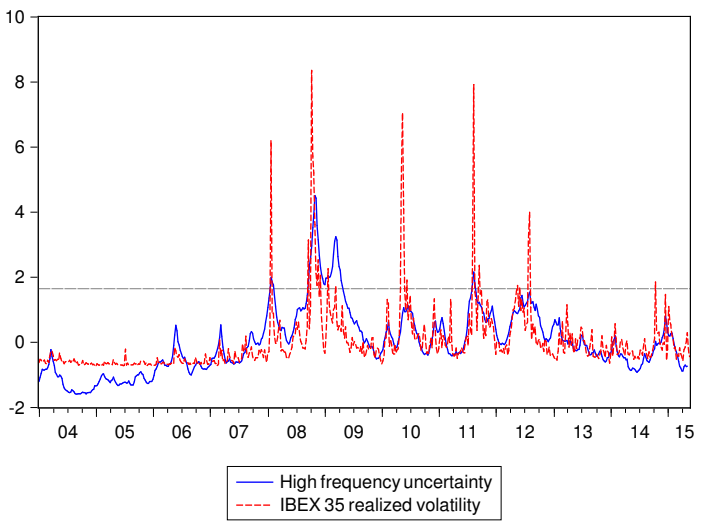

(a) Spain, comparison with stock market volatility

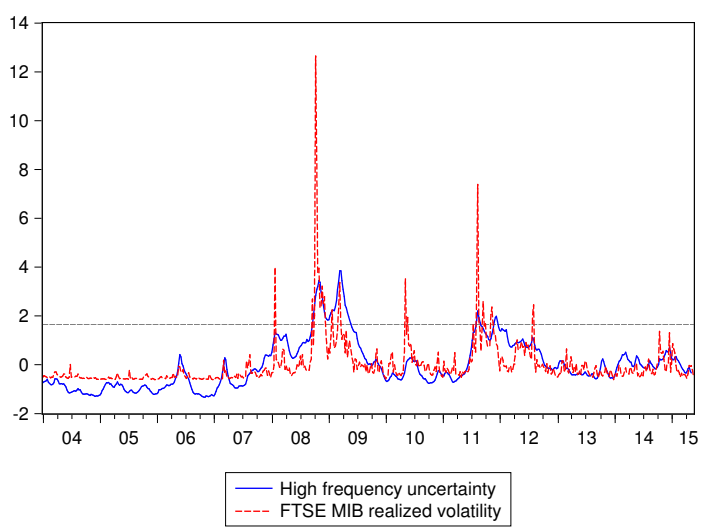

(c) Italy, comparison with stock market volatility

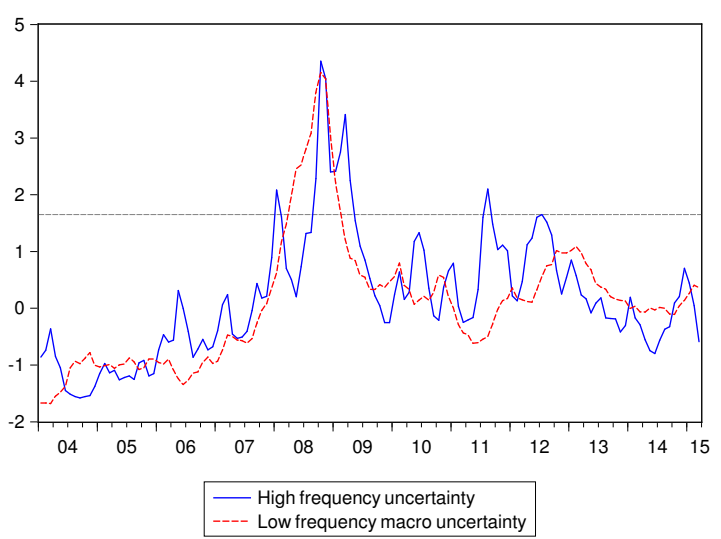

(b) Spain, comparison with low freq. macro uncertainty

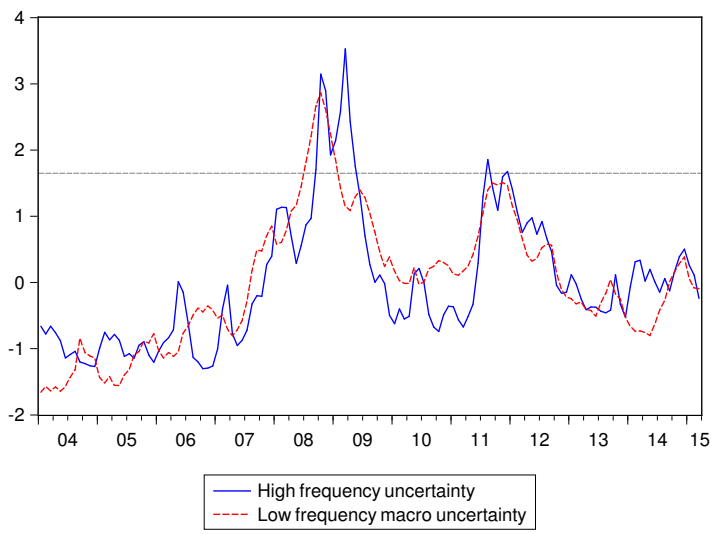

(d) Italy, comparison with low freq. macro uncertainty

Figure D.10: Comparison of our high frequency uncertainty measure with realized stock market volatility and low frequency macroeconomic uncertainty, data standardized and horizontal dashed line indicating 1.65 standard deviations. 

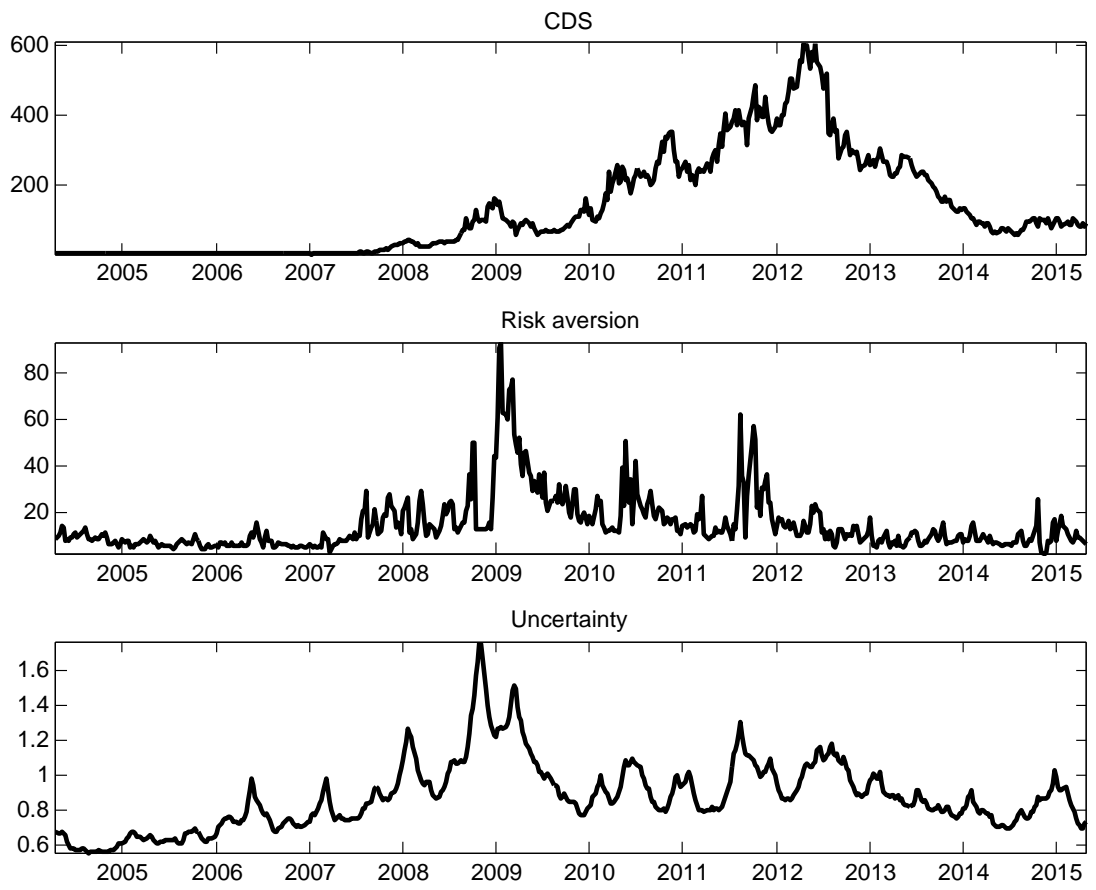

(a) Spain
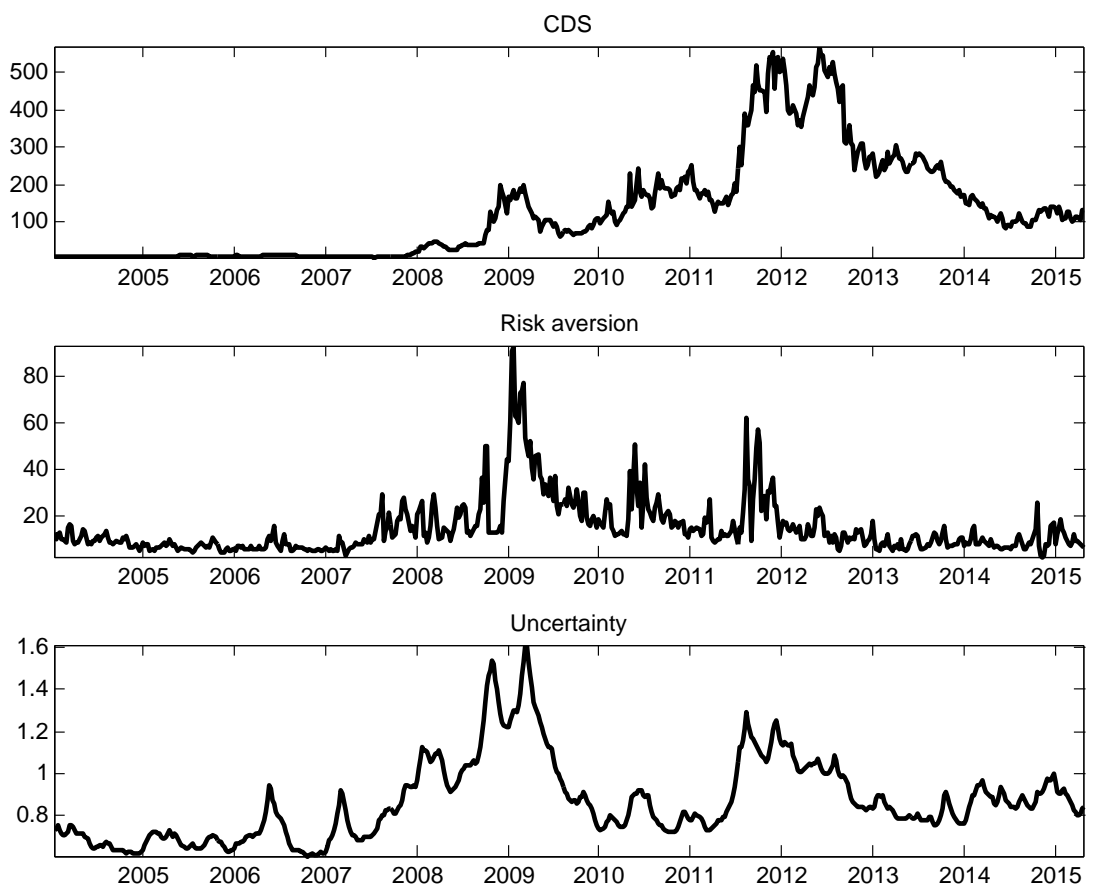

(b) Italy

Figure D.11: Endogenous variables entering the MSH-VAR models 

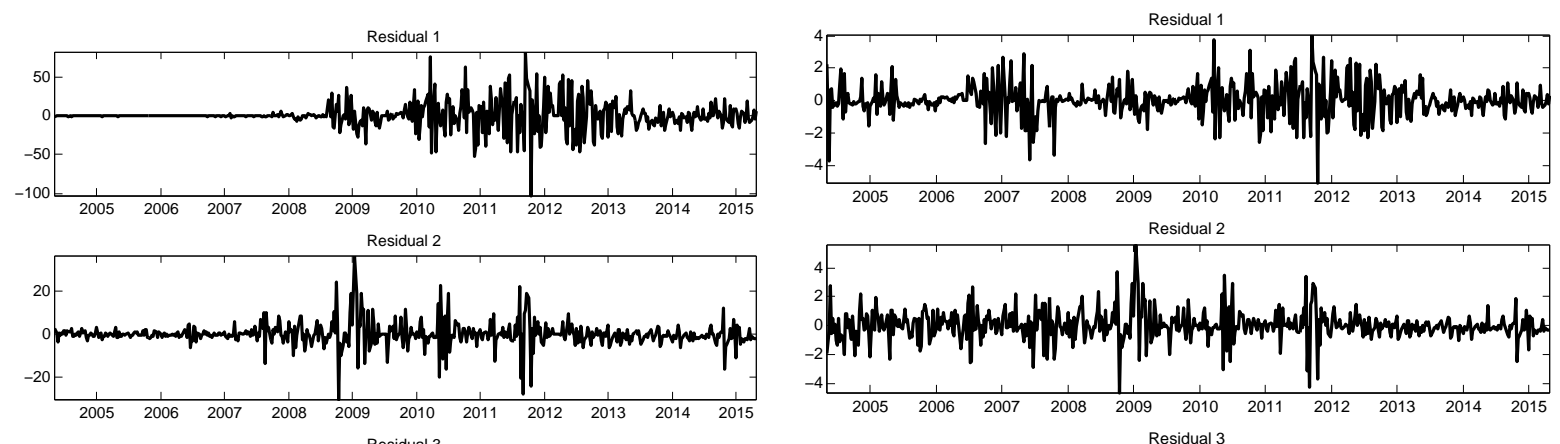

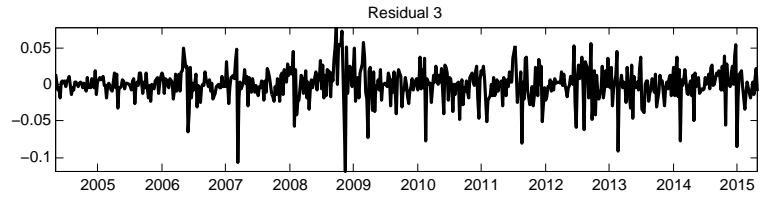

(a) Spain, residuals
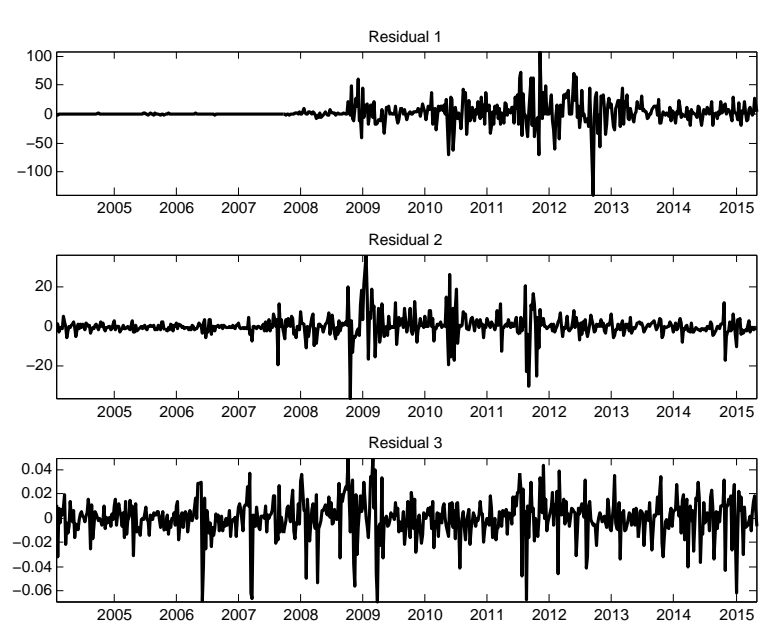

(c) Italy, residuals

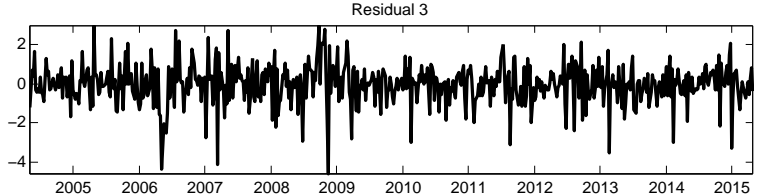

(b) Spain, standardized residuals
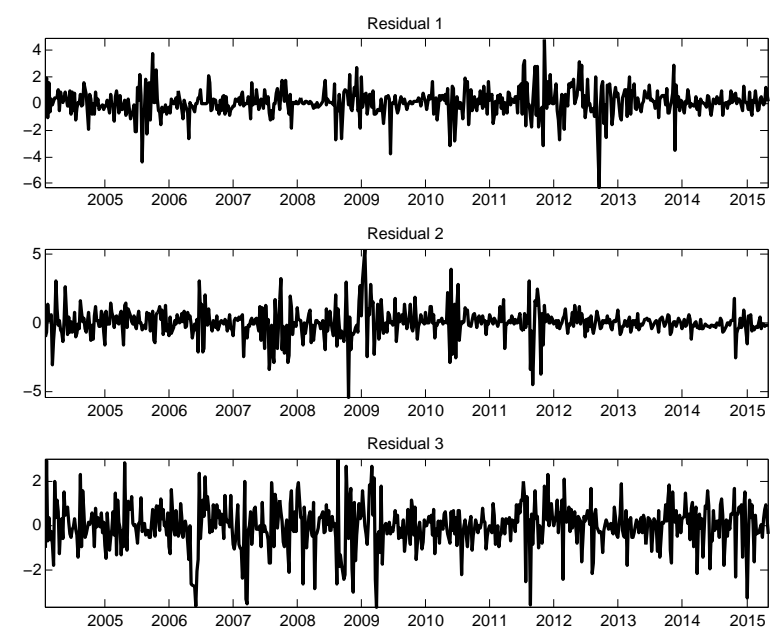

(d) Italy, standardized residuals

Figure D.12: Residuals and standardized residuals from the MSH-SVAR models 

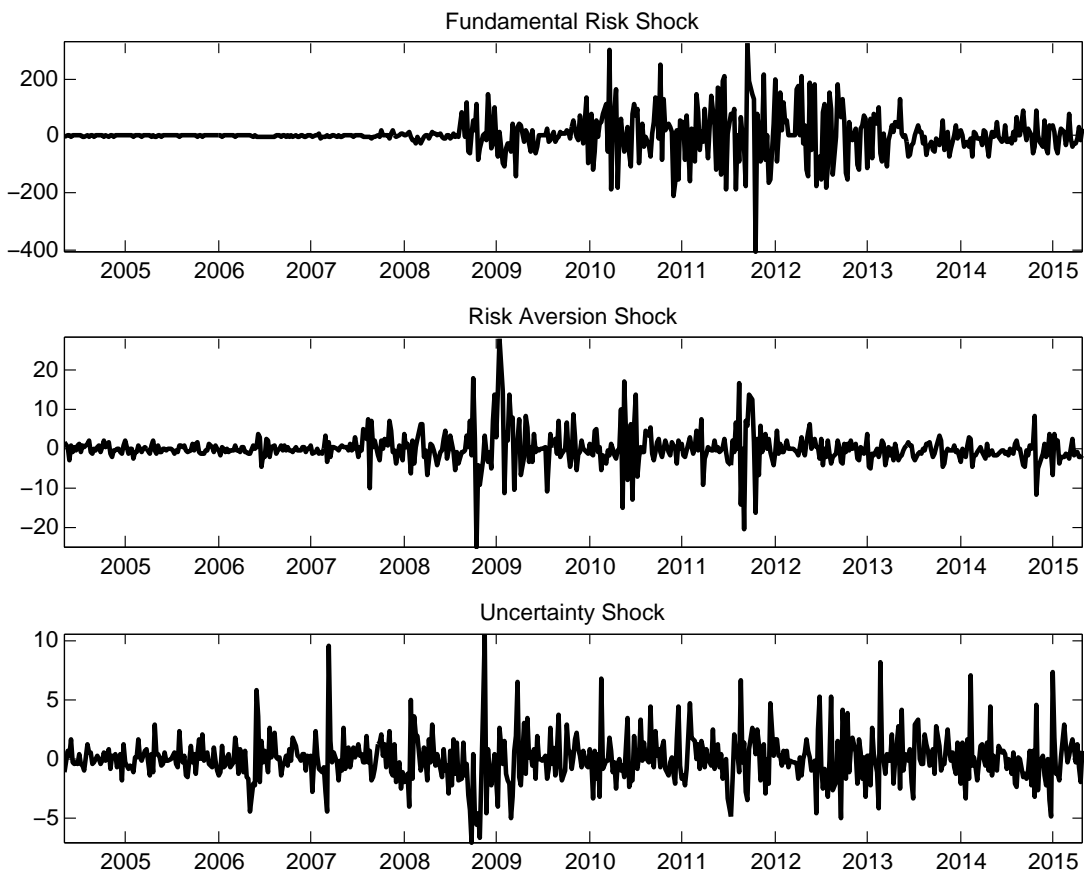

(a) Spain
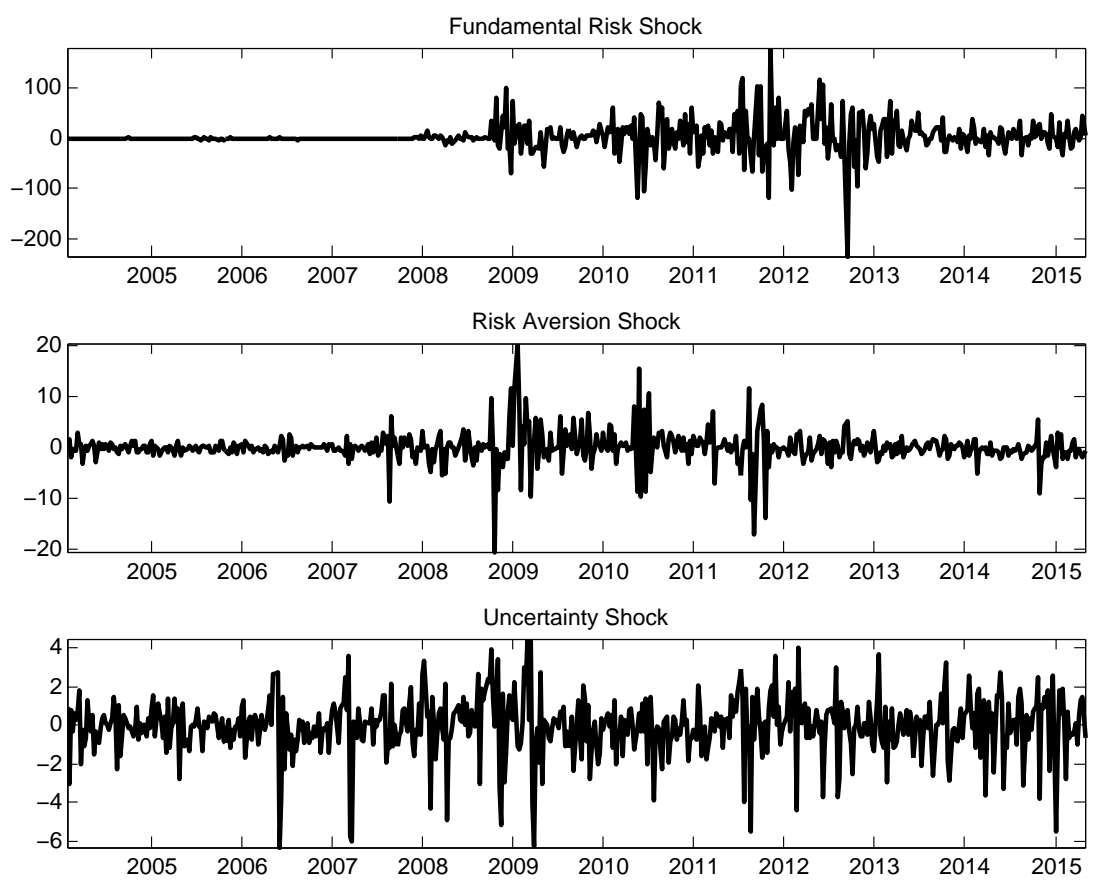

(b) Italy

Figure D.13: Structural shocks uncovered from the MSH-SVAR model 

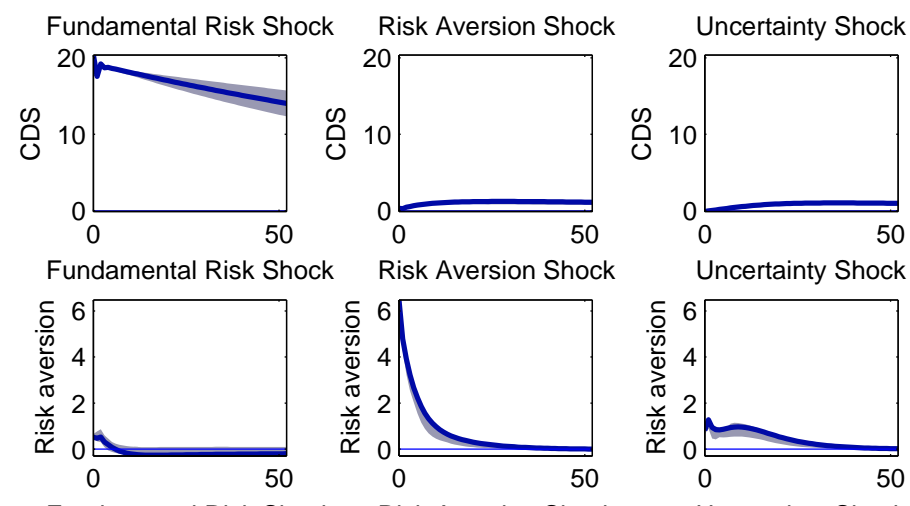

Fundamental Risk Shock Risk Aversion Shock
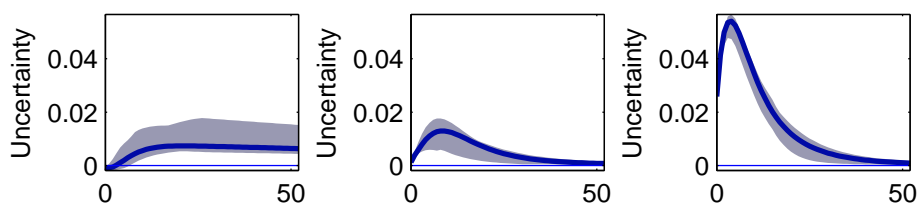

(a) Spain
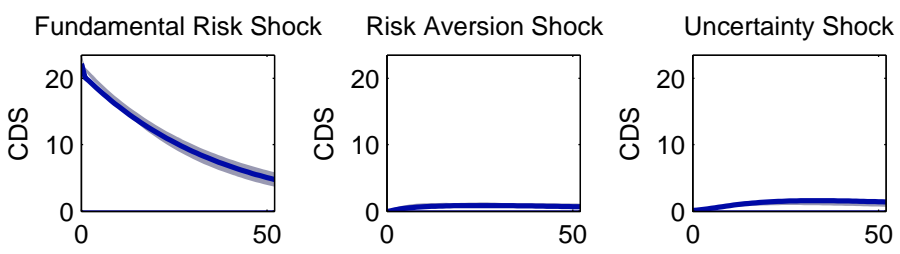

Fundamental Risk Shock
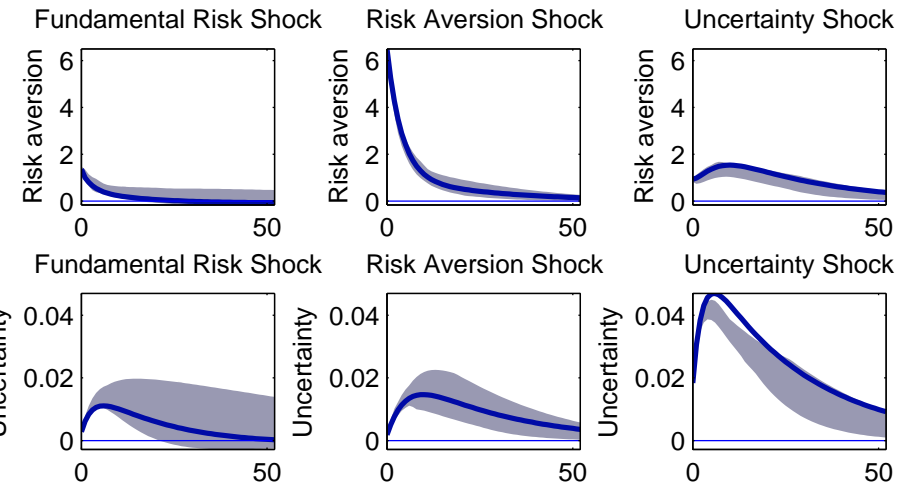

(b) Italy

Figure D.14: Impulse responses with $68 \%$ confidence intervals based on 1000 bootstrap replications, high volatility state 